TITLE:

\title{
Numerical simulations for the effects of normal loading on particle transport in rock fractures during shear
}

$\operatorname{AUTHOR}(\mathrm{S}):$

KOYAMA, T; LI, B; JIANG, Y; JING, L

\section{CITATION:}

KOYAMA, T ... [et al]. Numerical simulations for the effects of normal loading on particle transport in rock fractures during shear. International Journal of Rock Mechanics and Mining Sciences 2008, 45(8): 1403-1419

\section{ISSUE DATE:}

2008-12

URL:

http://hdl.handle.net/2433/93462

\section{RIGHT:}

Copyright (C) 2008 Elsevier Ltd; This is not the published version. Please cite only the published version.; この論文は出版社版でありません。引 用の際には出版社版をご確認ご利用ください。 


\section{Numerical simulations for the effects of normal loading on particle transport in rock fractures during shear}

T. Koyama ${ }^{a^{*}}$, B. Li ${ }^{b}$, Y. Jiang ${ }^{b}$ and L. Jing ${ }^{\mathrm{a}}$

${ }^{a}$ Engineering Geology and Geophysics Research Group, Department of Land and Water Resources Engineering, Royal Institute of Technology, KTH, S-100 44, Stockholm, Sweden

${ }^{\mathrm{b}}$ Faculty of Engineering, Nagasaki University, Nagasaki, 852-8521, Japan

* Corresponding author.

Tomofumi Koyama

Department of Urban and Environment Engineering,

Kyoto University

Nishikyo-ku, Kyoto, 615-8540, Japan

Tel.: +81-75-383-3308

Fax: $+81-75-383-3307$

E-mail address: koyama@geotech.kuciv.kyoto-u.ac.jp (T. Koyama)

Resubmitted to IJRMMS on the 19th of January, 2008 


\begin{abstract}
The fluid flow and tracer transport in a single rock fracture during shear processes has been an important issue in rock mechanics and is investigated in this paper using Finite Element Method (FEM) and streamline particle tracking method, considering evolutions of aperture and transmissivity with shear displacement histories under different normal stresses, based on laboratory tests.

The distributions of fracture aperture and its evolution during shear were calculated from the initial aperture fields, based on the laser-scanned surface roughness features of replicas of rock fracture specimens, and shear dilations measured during the coupled shear-flow tests in laboratory. The coupled shear-flow tests were performed under two levels of constant normal loading (CNL). A special algorithm for treating the contact areas as zero-aperture elements was used to produce more accurate flow field simulations by using FEM. The simulation results agreed well with the flow rate data obtained from the laboratory tests, showing that complex histories of fracture aperture and tortuous flow channels with changing normal stresses and increasing shear displacements for the flow parallel with the shear direction. The flow perpendicular to the shear direction was also predicted and normalized flow rates were compared with those for the flow parallel with the shear direction. A greater increase is observed in the direction perpendicular to the shear direction due to the significant flow channels newly created by shear. This clearly shows the shortcomings of the conventional coupled shear-flow tests in a laboratory with flow in direction parallel with the shear direction.

From the obtained flow velocity fields, the particle transport was predicted by using a streamline particle tracking method with calculated flow velocity fields (vectors) from the flow simulations, obtaining results such as flow velocity profiles, total flow rates, particle travel time, breakthrough curves and the Péclet number, $P e$, respectively. Analyzing breakthrough curves for the unidirectional particle transport, the transport behavior in the fracture is also anisotropic and advective transport is more dominant in the direction parallel with the shear direction. The effect of normal stress on the particle transport is significant and dispersion becomes larger with increasing normal stress.

The scientific findings from these studies provided new insights to the physical behavior of fluid flow and mass transport in rock fractures that is the scientific basis for many rock mechanics problems at the fundamental level, and with special importance to rock engineering problems.
\end{abstract}

Keywords: Rock fracture, coupled stress-flow test, shear displacement, fluid flow, particle transport, finite element method (FEM), particle tracking method, Reynolds equation, streamline/velocity dispersion. 


\section{Introduction}

The coupled processes of shear displacement, fluid flow and solute/particle transport processes in rock fractures are increasingly important research topics mainly due to the demands for design, construction, operation and performance/safety assessments of underground radioactive waste repositories and other civil and environmental engineering works such as underground storage caverns and oil/gas reservoir engineering.

Many efforts have also been made to test fluid flow and tracer transport processes in rock fractures, with or without flow visualization and normal loading [1-3]. It was found that fluid flows in rock fractures through connected and tortuous channels that bypass the contacts areas. However, the effects of contacts and the channel distribution patterns on the fluid flow and tracer transport processes in a rock fracture, and their change due to both normal stress and shear displacements, have not been fully understood, even though the effect of the mechanical processes on the fluid flow and transport phenomena has been investigated experimentally and numerically by considering normal stresses without shear [4-6] or shear displacement without (or very weak) normal stress $[5,7-8]$. This is mainly due to the difficulties of quantitative measurements of changing fracture surface roughness and aperture during laboratory coupled stress-flow tests, especially the contact areas, as well as a number of technical difficulties in laboratory shear-flow testing, most notably the sealing of fluid during shear. The studies represented in this paper highlights a significant step forward in deepening our qualitative understanding of the hydro-mechanical and transport behavior of rough rock fractures.

Numerical modelling for fluid flow and solute transport in rough rock fractures has been carried out before [4, 9-13]. Many of these studies used geostatistical or fractal methods to artificially generate fracture geometry/aperture fields. They concluded that due to the roughness of the fractures, fluid flow follows some dominant paths or channels, which offer the least resistance. Some sophisticated reactive transport models have been proposed, considering also matrix diffusion and sorption [14-16]. However, the effects of stress history, especially shearing processes, on the flow and particle transport, have not been taken into account. On the other hand, flow simulations considering the effect of normal and shear stresses were reported, using scanned/artificially generated rough fracture surfaces [17-20]. However, in these works, due to numerical difficulties, very small aperture values were assigned to contact areas to avoid solving ill-formed matrix equations for fluid flow. Therefore, there still exist some artificial flows inside the contact areas, despite that they are small in magnitudes. Such treatment of contact areas as non-zero aperture elements is not only physically nonrealistic, but may have more significant effects on the particle transport simulations since such fluid-conducting contact areas will change the particle transport paths, which may affect the estimations of travel time, dispersivity and tortuosity. The methodology to evaluate the variable aperture under normal and shear loading is an essential issue in such studies.

The overall objective of this paper is to study coupled fluid flow and particle transport processes in rough fractures during shear with a constant normal loading condition (CNL), both experimentally and numerically, with a more realistic treatment of contact areas. The laboratory tests of fluid flow in fracture replicas under different normal stresses of 1.0 and 1.5 MPa were simulated by using numerical simulations with Finite Element Method (FEM), considering simulated evolutions of aperture and transmissivity with large shear 
displacements of $18 \mathrm{~mm}$. The distributions of fracture aperture and its evolution and the flow rate during shearing were calculated from the initial aperture and shear dilations, and compared with results measured in the laboratory coupled shear-flow tests. The contact areas in the fractures were treated correctly with zero aperture values with a special algorism so that more realistic flow velocity fields and potential particle paths were captured, for more realistic simulations of particle transport. The particle transport was predicted by the streamline particle tracking method with calculated flow velocity fields (vectors) from the flow simulations, obtaining results such as flow velocity profiles, total flow rates, particle travel time, breakthrough curves and the Péclet number, $P e$, respectively.

\section{The experimental study}

\subsection{Sample preparations}

A natural rock fracture surface, labeled J1, were taken from the construction site of Omaru power plant in Miyazaki prefecture in Japan and used as the parent fracture surface in this study as shown in Fig. 1. This natural fracture surface is not rough $(\mathrm{JRC}=0-2)$ without major structural non-stationarities. Three replicas of fracture specimens were manufactured with the $\mathrm{J} 1$ as the parent fracture surface. The specimens are $100 \mathrm{~mm}$ in width, $200 \mathrm{~mm}$ in length and $100 \mathrm{~mm}$ in height, respectively. They were made of mixtures of plaster, water and retardant with weight ratios of 1: 0.2: 0.005 . The surfaces of the J1 specimen were firstly re-cast by using resin, and then the two parts of a fracture specimen were manufactured based on the resin replica. By doing so, the two parts of each fracture specimens used in this study are almost perfectly mated as the initial condition with contact ratio very close to 1.0 [21-24]. Using a three-dimensional laser scanning profilometer system with an accuracy of $\pm 20 \mu \mathrm{m}$ and a resolution of $10 \mu \mathrm{m}$, the $\mathrm{J} 1$ surface was measured with an interval of $0.2 \mathrm{~mm}$ in both $x$ and $y$-axes [21-24].

\subsection{Coupled shear-flow-tracer tests under CNL conditions - experimental procedure}

A series of coupled shear-flow tests under constant normal stresses (CNL) was carried out using the newly developed apparatus in Nagasaki University, Nagasaki, Japan [21-22]. Two constant normal stresses of $1 \mathrm{MPa}$ and $1.5 \mathrm{MPa}$ were applied to the fracture specimen during the tests. The flow rates were measured during the shear-flow tests with a constant hydraulic head difference of $0.1 \mathrm{~m}$ during shear up to a total shear displacement of $18 \mathrm{~mm}$, with a $1 \mathrm{~mm}$ interval of shear displacement. The flow direction is parallel with the shear direction. Since the sizes of the upper and lower parts of the specimens are the same, the actual contact lengths decrease linearly during shear. As a result, the hydraulic gradient was not constant (progressively increasing from 0.5 to 0.55 ) during shear so that the back-calculations of flow rates and hydraulic conductivities were adjusted to this condition.

\subsection{Evaluation of aperture evolution during shear-flow-tracer tests}

The aperture (or transmissivity) evolution during shear is the key issue for simulating fluid flow and mass transport in rock fractures. In common practice, the mean transmissivity or hydraulic aperture of a sample can be calculated from measured flow rate from which the 
mean aperture is back-calculated by assuming the validity of the cubic law. The detailed distribution of aperture/transmissivity inside the fracture cannot be directly measured during shear tests, but could be accurately simulated by numerical simulations if adequate topographical data of the fracture surfaces are available. During the shear-flow tests, the mean mechanical aperture, $b_{m}$, was assessed based on measured values of the items in the following equation [25]:

$$
b_{m}=b_{0}-\Delta b_{n}+\Delta b_{s}
$$

where $b_{0}$ is the initial mechanical aperture, $\Delta b_{n}$ is the change of aperture by normal loading (such as closure or opening), and $\Delta b_{s}$ is the change of aperture by shearing (dilation).

The initial aperture $b_{0}$ under a certain normal stress can be obtained by using the measured normal stress-normal displacement curves (Fig. 2). Before starting a direct shear test, a series of cyclic normal loading tests for the fracture are usually carried out. The purpose for such tests is not only to evaluate fracture deformability against the normal stress but also to evaluate the initial condition of the fracture in terms of normal closure. In this study, we applied four cycles of normal loading and unloading processes (up to maximum normal stress of $4 \mathrm{MPa}$ ). The curve a in Fig. 2 represents the normal stress-displacement curve obtained after the fourth cycle of normal loading-unloading, which includes deformations of both fracture and intact material. The deformation (linear elastic deformation) of the intact material can be expressed as an asymptote of curve a (line b) or can be measured separately (line b'). The pure deformation of the fracture (curve c) can be calculated by reducing line b' from curve a' (curve a shifted to the origin of the coordinate axes). The fracture deformation against normal stress (curve c) is usually fitted by a hyperbolic function proposed by Bandis et al. [26]) and the maximum closure of the fracture can be defined as an asymptotic value, $\mathrm{V}_{\mathrm{m}}$. In this study, we assumed that this maximum closure is equal to the opening of the fracture without any normal load and the change of fracture aperture (closure) becomes a function of normal stress, represented by curve c' (as a mirror image of curve c). The initial aperture, $b_{0}$, at a certain initial normal stress, $\sigma_{0}$, can be calculated from curve c'. Under the constant normal loading (CNL) conditions, $\Delta b_{n}$ could be zero when the initial aperture under a certain normal stress is considered in $b_{0}$, and $\Delta b_{s}$ is the measured normal displacement (dilation) during shear test. The evaluated mean normal displacement of the sample during shear is then used in the numerical simulations for evaluating shear-induced changes of mechanical apertures of elements in the FEM models.

\section{Numerical simulations}

\subsection{Governing equations}

When flow velocity is low and the fracture surface geometry does not vary too abruptly the Reynolds equation can be used, instead of the full Navier-Stokes equations, to describe the flow in fractures [17, 27]. Assuming that the flow of an incompressible fluid through the fracture follows the cubic law, in a steady state, the governing equation can be written as

$$
\frac{\partial}{\partial x}\left(T_{x x} \frac{\partial h}{\partial x}\right)+\frac{\partial}{\partial y}\left(T_{y y} \frac{\partial h}{\partial y}\right)+Q=0
$$

where $Q$ is the source/sink term (positive when fluid is flowing into the fracture), and $T_{x x}$ and $T_{y y}$ are the fracture transmissivity $\left[\mathrm{L}^{2} \mathrm{~T}^{-1}\right]$ in $x$ - and $y$-directions, respectively. In this paper, 
the local transmissivity at each element of the FEM model of the fracture is assumed to be equal in $x$ - and $y$-directions for simplicity and is defined by

$$
T_{x x}=T_{y y}=T(x, y)=\frac{\rho_{f} g b^{3}}{12 \mu},
$$

where $\mu$ is the dynamic viscosity $\left[\mathrm{ML}^{-1} \mathrm{~T}^{-1}\right], \rho_{f}$ the fluid density $\left[\mathrm{ML}^{-3}\right], g$ the gravitational acceleration $\left[\mathrm{LT}^{-2}\right]$, and $b$ the local fracture aperture [L] (calculated using Eq.(1)), respectively. The local transmissivity of the fracture can be determined element by element, according to the aperture evaluation results. In this study, the density and dynamic viscosity of water at $10^{\circ} \mathrm{C}$ were used as $\rho_{f}=9.997 \times 10^{2} \mathrm{~kg} / \mathrm{m}^{3}$, and $\mu=1.307 \times 10^{-3} \mathrm{~Pa} \cdot \mathrm{s}$, respectively, with a gravitational acceleration of $g=9.807 \mathrm{~m} / \mathrm{s}^{2}$.

To solve Eq. (2), the commercial FEM software, COMSOL Multiphysics [28] was used to simulate flow processes during shear. Since the number of the scanning points on the surface for representing the roughness and calculating the aperture is very large $(2000 \times 1000$ points $)$ for each sample, even though they are regularly distributed over the specimen area. The digitalized aperture fields of the fracture specimens were divided into $20000(200 \times 100)$ small square elements of an edge length of $1.0 \mathrm{~mm}$, as the FEM model. The mean aperture of each element was calculated at each shear displacement interval $(1.0 \mathrm{~mm})$. Shearing is simulated by moving the upper surface by a horizontal translation of $1 \mathrm{~mm}$ in the shear direction, then uplifting by the dilation increment according to the measured mean shear dilation value at that shear interval in the experiment. For the initial condition (with normal loadings of $1 \mathrm{MPa}$ and $1.5 \mathrm{MPa}$ without shear displacement), the upper and lower surfaces were superimposed iteratively so that the average of the aperture at all measuring points is equal to the initial mechanical aperture $b_{0}$ (in Eq. (1)).

When translational shear and dilation displacements are simulated numerically as mentioned above, the previous contact pattern is broken and some new voids and new contact areas are generated at each shear step, and the contact conditions and apertures must be re-evaluated for all elements. When an element has its two opposing surfaces separated, it represents a void zone and its aperture is evaluated as the mean distance in the direction normal to the mean plane of the fracture. When its two opposing surfaces are just in touch or penetrate each other with negative values of contact distance, a contact zone is created and assigned with a zero aperture. In reality the latter represents surface damage/asperity degradation. All void elements were assumed to be parallel plate models obeying the cubic law locally with a constant mean aperture [17, 27, 29-30].

In the numerical modelling of fluid flow, effect of gouge materials is ignored since negligible amount of gouge materials were observed during tests. Asperity deformation was not considered but damage at contact points were partially approximated by removing the overlapping parts of contacting asperities in the contact elements. Their effects on shear dilation and fluid flow are, however, reflected in the measured total flow rate and normal displacement values.

\subsection{Boundary conditions and the treatment of contact areas}

Both flows parallel with and perpendicular to the shear direction were considered in the flow simulations by fixing the initial hydraulic heads of $0.1 \mathrm{~m}$ and $0 \mathrm{~m}$ along the left- and 
right-hand boundaries for the flow parallel with the shear direction (Fig. 3a), and the bottom and top boundaries for the flow perpendicular to the shear direction (Fig. 3b), respectively. The flow boundary condition for the flow parallel with the shear direction is the same as the one used in the laboratory coupled shear-flow tests. The flow boundary condition for the flow perpendicular to the shear direction has many technical difficulties to overcome in the laboratory coupled shear-flow tests and therefore, no measurements for such test conditions were made successfully in the laboratory tests. Hence, the presented simulation results for fluid flow perpendicular to the shear direction are pure predictions.

The contact areas/elements were numerically eliminated from the calculation domain and their boundaries were treated as additional internal boundaries with a zero normal flux condition $\partial h / \partial n \equiv(\nabla h) \cdot \mathbf{n}=0$, where $\mathbf{n}$ is the outward unit normal vector, in order to satisfy conditions of no flow into or out of the contact areas [29-30, 31].

Since irregular triangle elements were used in the COMSOL modeling for fluid flow (see Fig. $3 \mathrm{c}$ ), which is more flexible for treatment of the complex contact geometry with much finer FEM meshes around the contact areas, the regular rectangular grid aperture data evaluated using the approach described above paragraph was linearly interpolated for the triangle elements. This technique was applied to evaluate the elemental transmissivity, which can be calculated from aperture value using Eq. (3), assuming local validity of the Reynolds equation, at each shear displacement interval to simulate the fluid flow through the fracture during shear.

\subsection{Particle transport simulations - particle tracking method}

We assumed that the volumetric concentration $c$ of a solute (particles) can be divided into two parts, one related to advection, $\bar{c}$, and the other to dispersion, $\widetilde{c}$ [32-33]:

$$
c\left(x_{i}, t\right)=\bar{c}\left(x_{i}, t\right)+\widetilde{c}\left(x_{i}, t\right) .
$$

Then, the advection-dispersion equation of transport can be separated into two independent equations: a purely hyperbolic 'advection equation' in terms of $\bar{c}$

$$
\frac{d \bar{c}}{d t}=\frac{\partial \bar{c}}{\partial t}+\frac{V_{i}}{R} \frac{\partial \bar{c}}{\partial x_{i}}=-\lambda \bar{c}
$$

and a predominantly parabolic 'dispersion equation' in terms of $\widetilde{c}$

$$
R \rho \theta \frac{d \widetilde{c}}{d t}=\frac{\partial}{\partial x_{i}}\left(\rho \theta D_{i j} \frac{\partial c}{\partial x_{i}}\right)-R \rho \theta \lambda \widetilde{c}+Q_{c},
$$

where $c$ is the volumetric concentration, $R$ is the retardation factor $[-], \rho$ is the fluid density $\left[\mathrm{ML}^{-3}\right], \theta$ is the volume water content $[-], t$ is time $[\mathrm{T}], D_{i j}$ is the dispersion tensor $\left[\mathrm{L}^{2} \mathrm{~T}^{-1}\right], V_{i}$ is the actual velocity $\left[\mathrm{LT}^{-1}\right], \lambda$ is the decay rate $\left[\mathrm{T}^{-1}\right]$, and $Q_{c}$ is the source/sink term per unit time, respectively. The parameters $R$ and $\lambda$ are greater than or equal to 0 , and $D_{i j}$ is a symmetric and positively semi-definite tensor.

As the focus of this research is to gain basic knowledge about particle transport phenomena in a rough fracture during mechanical shear, rather than developing sophisticated transport 
simulation methods, a straightforward and highly simplified transport modeling approach was adopted. In this study, a Lagrangian approach considering only the advection process (Eq. (5)) was adopted. The random dispersion due to diffusion of the solute particles within the fluid in fracture, and other retardation mechanisms such as sorption or decay, were not taken into account. As the steady-state fluid flow was assumed, particle tracking along the streamlines was used. An iteration process was used to advance particles along the streamlines in the flow field in order to calculate their travel paths and travel time, and then the shear-induced changes in the breakthrough curves and Péclet number of the particle motion were calculated.

With the above assumptions and simplifications, for the problem of particle advection in a steady state fluid flow field, assuming $\lambda=0$ in Eq. (5), the new position of a particle $j$ in the tracking step $i+1$ is given by

$$
\mathbf{x}_{j}^{i+1}=\mathbf{x}_{j}^{i}+\int_{t^{i}}^{t^{i+1}} \frac{\mathbf{V}}{R} d t
$$

where $\mathbf{x}_{j}^{i+1}$ is the position vector of the particle $j$ after the iteration step $i+1$ and $\mathbf{x}_{j}^{i}$ is the position vector of the particle $j$ in iteration step $i$ and $\mathbf{V}$ is the velocity vector. In this case, $R=1$. The integration of Eq. (7) leads to the mean flow velocity value $\bar{V}$ for the element concerned. Hence, the increment of residence time can be calculated approximately at each iteration as follows:

$$
t_{j}^{i}=\frac{\mathbf{x}_{j}^{i+1}-\mathbf{x}_{j}^{i}}{\bar{V}} .
$$

The fluid flow velocity field at each shear displacement step obtained by FEM simulation was provided as input data, element-by-element, for particle tracking simulations. The residence time in each element was calculated from the travel distance and its corresponding velocity. The total particle travel time was calculated as the sum of the residence time of all the elements passed through by each particle (Eq. (8)), as given by

$$
t_{j}=\sum_{i=1}^{m} t_{j}^{i}
$$

where $t_{j}$ is the travel time of particle $j, t_{j}^{i}$ is the time of particle $j$ in iteration $i$ and $m$ is the number of iterations made by particle $j$.

For the particle injection at the inlet boundary, the number of particle injected at the elements along the inlet boundary was proportional to the element's flow rates, which were solved by using the hydraulic boundary conditions while solving the Reynolds equation. This means that more particles were attracted to the elements of higher flow rates. The locations of particles injections were arranged regularly at an interval of $1.0 \mathrm{~mm}$ along the inlet boundary, which means that there are 100 injection points for the flow parallel with the shear direction, and 200 injection points initially for flow perpendicular to the shear direction and the number decrease with shear displacements (182 injection points after $18 \mathrm{~mm}$ shear displacement), respectively. Figure 4 shows the calculation method for the number of particles that were introduced at the inlet boundary for the particle transport in parallel with ( $x$-direction) and perpendicular ( $y$-direction) to the shear direction. The effects of different particle injection methods on the breakthrough curves and transport properties were also extensively investigated in [34]. 
From the particle tracking simulations, travel time for each particle was obtained from Eq. (9) and can be evaluated for breakthrough curves, represented as the percentages of the particles collected at the outlet as functions of time. The Péclet number can be evaluated in terms of the variance and the mean value of the travel time using the following equation [35]:

$$
P e=2 \cdot\left(\frac{\bar{t}}{\sigma_{t}}\right)^{2},
$$

where $\sigma_{t}^{2}$ and $\bar{t}$ are the variance and mean travel time, respectively.

\section{Results}

\subsection{Numerical simulations of the laboratory coupled shear-flow tests}

The results of flow velocities are superimposed in Fig. 5, with an arrow at the bottom indicating the overall flow direction as parallel with the shear direction. The color intensity of the background in the flow areas indicates the magnitude of local transmissivities (see the legend in the figure). In the figure, the white 'islands' indicate the contact areas. Figure 5a and $\mathrm{b}$ show the flow velocity fields with transmissivity evolutions at shear displacements of $1,2,5$, 10 and $15 \mathrm{~mm}$ for fracture specimen, $\mathrm{J} 1$ under different constant normal stress of $1 \mathrm{MPa}$ (J1-1) and 1.5 MPa (J1-2), respectively. These figures clearly show the influences of morphological behaviors of fracture specimens on the development of aperture distributions and fluid flow fields.

The surface of specimen $\mathrm{J} 1$ is relatively smooth and flat. At a shear displacement of $1 \mathrm{~mm}$, the contact areas were widely and almost uniformly distributed over the whole fracture surface and actually blocked the fluid flow totally without any continuous flow path formed (first figure of Fig. 5a). More continuous flow paths started to form at a shear displacement of $2 \mathrm{~mm}$, and continued to grow into main flow paths with continued decrease of contact areas and increase of transmissivity, with increasing shear displacement (see the last four figures of Fig. 5a). Two outlet spots on the outlet boundary of the sample at the upper left and lower left corners of the sample can be observed. From Fig. 5b, due to the much increased contact areas and much reduced transmissivity, there was no fluid flow going through the fracture specimen (contact areas blocking the fluid flow totally) up to shear displacement of $2 \mathrm{~mm}$, and significant flow paths can only be detected at a shear displacement of $5 \mathrm{~mm}$, as shown in Fig. $5 \mathrm{~b}$.

In both cases, fluid flows bypassed the contact areas with less resistance and main flow paths were limited only in a few high transmissivity areas (flow channels). As a result, flow patterns (or stream lines) became very tortuous. This phenomenon is well-known as 'channelling effect' [36].

The flow rates at the outlet boundary (along $x=0$ ) for all test cases with two normal stresses were compared between laboratory tests and numerical simulations as shown in Fig. 6 and Table 1. Note that the zero flow rates cannot be plotted in the figure with log-scaling in the axes for the flow rate. 
The general behaviors of the flow rate variation with shear displacement under different normal stresses were captured for the tested specimens, with varying degrees of general agreements with the measured data. The flow rate increases very sharply during the early stage of shear (after a shear displacement of $2 \mathrm{~mm}$ or $3 \mathrm{~mm}$ ) and continues to increase but with a progressive reduction of gradient. A 'sill' may be approximated for specimen J1 at about a shear displacement of $10 \mathrm{~mm}$. The general increase of flow rate is about 4-5 orders of magnitude from the initial state before shear. The general behaviors agree with the general understanding of the flow behavior of rock.

The significant disagreement occurs at early stages of shear (particularly at the start of shear) and at large displacements (after shear displacement of $15 \mathrm{~mm}$ ). Please note that the numerical simulations were not calibrated with test results but pure predictions with assumptions of zero apertures (therefore zero flow rate) as the initial state for all cases. The predicted flow rates and hydraulic aperture from numerical simulations are underestimated for the two normal stress cases. The deviations may be caused by mainly the following four reasons:

1) uneven dilation (tilting of the fracture sample) and/or local surface damage in the fracture during coupled shear-flow tests, which were not measured in tests and therefore not considered in the numerical predictions;

2) relocation offsets by experimental difficulties to realize fully mated initial condition (especially for fracture specimens of smoother surfaces) still exists, but not measured, even after applying weak cyclic normal loading before the shear tests;

3 ) ignorance of mechanical deformation of asperities under normal loading in the numerical predictions, which may be important for relatively soft materials of concrete replicas;

4) square elements with edge length of $1 \mathrm{~mm}$ for the smallest contact area may be too coarse. As a result, too much fluid flow might be blocked by the contact areas, especially at small shear displacement stages;

Among the four reasons mentioned above as possible sources of discrepancies in the results of predicting flow rates and hydraulic apertures, the relocation error (offsets) and uneven dilation might be most significant at early stage of shear (before shear displacement of $2 \mathrm{~mm}$ ) and at large shear displacement (after shear displacement of $15 \mathrm{~mm}$ ), respectively. The ignorance of asperity deformation may not be very significant, since generation of gouge materials was not significant as observed in laboratory tests. The effects of relocation offset and tilting could be considered readily in model calibrations as long as the initial aperture and tilting direction and extent can be quantified during testing, but the asperity deformation and damage cannot be properly considered at present due to difficulties in measurements.

\subsection{Simulation for shear-induced flow anisotropy}

The simulated results of flow velocity fields with transmissivity evolutions when the overall flow direction was perpendicular to the shear direction are shown in Fig. 7. Figures $7 \mathrm{a}$ and $7 \mathrm{~b}$ show the flow velocity fields with transmissivity evolutions as the background color contours at shear displacements of 1, 2, 5, 10 and $15 \mathrm{~mm}$ for fracture specimen $\mathrm{J} 1$ under two normal stresses of $1 \mathrm{MPa}(\mathrm{J} 1-1)$ and $1.5 \mathrm{MPa}(\mathrm{J} 1-2)$, respectively. These figures clearly show the more significant channeling flows in the direction perpendicular to the shear direction. 
The contact areas are widely and uniformly distributed over the whole fracture specimen and actually blocked the fluid flow totally without any continuous flow path (first figure of Fig. 7a). The continuous flow paths start to form at a shear displacement of $2 \mathrm{~mm}$, and continue to grow into two main flow paths with increasing shear displacement (see the last four figures of Fig. 7a). From Fig. 7b, due to the much increased contact areas and much reduced transmissivity, more tortuous flow can be observed at the shear displacement of $2 \mathrm{~mm}$. The same flow paths as shown in Fig. 7a can be observed, once significant flow paths created at a shear displacement of $5 \mathrm{~mm}$.

The two sets of simulation results for flow parallel with and perpendicular to the shear direction, as shown in Figs. 5 and 7, indicate completely different flow patterns. When the general flow direction is parallel with the shear direction (Fig. 5), the flow is more tortuous. When the general flow direction is perpendicular to the shear direction (Fig. 7), the overall flow field becomes more regular through connected higher transmissivity channels oriented in the direction perpendicular to the shear direction.

Two sets of the normalized flow rates calculated at two outlet cross sections, with different flow directions with respect to the shear direction, are compared for specimen, $\mathrm{J} 1$, as shown in Fig. 8, as functions of shear displacement. One set is the flow rate at position of $x=0$ for the fluid flow parallel with the shear direction (in the $x$-direction) and the other set is the flow rate at position $y=0.1 \mathrm{~m}$ for the fluid flow perpendicular to the shear direction (in the $y$-direction). The flow rates are normalized by dividing hydraulic gradient and edge length of the specimens in order to compare them directly, since the fracture samples are not square (the edge length is different) and therefore hydraulic gradient are different. For all specimens and shear displacements, the normalized flow rates perpendicular to the shear direction are larger than those parallel with the shear direction. The difference is from a factor of 5 to nearly 2-3 orders of magnitude.

The above results clearly illustrate the limitations of the traditional shear-flow tests using the boundary condition as shown in Fig. 3a, with fluid flow parallel with the shear direction. While such tests can capture the flow behavior in the shear direction, it can only be used to estimate the transmissivity of the fracture in that direction. The significant effects of shear dilation on flow in other directions, especially the direction perpendicular to shear direction, cannot be captured and therefore are often neglected. This shortcoming may lead to significant underestimation of the fluid transmissivity of the rock fractures during shearing processes.

\subsection{Particle transport simulations}

Particle transport simulations were performed for specimens J1 under two normal stresses of 1.0 $\mathrm{MPa}$ (test case J1-1) and 1.5 MPa (test case J1-2). As mentioned in section 3.3, the streamline particle tracking method was used to predict the particle movements for fluid flow both parallel with and perpendicular to the shear directions through the specimens at each shearing stage, with the fluid flow governed by the Reynolds equation. The locations of the particle injection points were evenly distributed with a $1.0 \mathrm{~mm}$ interval along the inlet boundary. The number of the particles is related to the local flow rates at the inlet boundary. 
Figures $9 \mathrm{a}$ and $9 \mathrm{~b}$ show the particle travel paths and their changes during shear for overall flow parallel with the shear direction for specimen J1 under normal stresses of 1.0 MPa and 1.5 MPa, respectively. From Fig. 9a, the particles start reaching the outlet boundary after a shear displacement of $2 \mathrm{~mm}$ and more continuous particle travel paths appear after a shear displacement of $3 \mathrm{~mm}$. The particle paths are very tortuous, but much less tortuous when the flow direction is perpendicular to the shear direction (Fig. 10a). At the shear displacement of $15 \mathrm{~mm}$, particle paths become more widely distributed (less localized) in the middle of the fracture sample (the bottom figure in Fig. 9). This is caused by more concentrated distributions of contact areas in the central part of the specimen J1. The effects of normal loading on the particle travel paths are clearly shown by comparing Fig. 9a and 9b, especially at the early stages of shear (less than $3 \mathrm{~mm}$ of shear displacement). Because of the higher normal load (Fig. 9b), the fracture aperture becomes smaller and the contact area becomes larger. Therefore, void space of the fracture becomes more complex and particle paths become more tortuous and varied.

Figures $10 \mathrm{a}$ and $10 \mathrm{~b}$ show the particle travel paths and their changes during shear for overall flow perpendicular to the shear direction for specimen $\mathrm{J} 1$, under different constant normal stress of 1.0 MPa and 1.5 MPa, respectively. Most particles travel through a couple of connected high transmissivity channels oriented almost perpendicular to the shear direction and reach to the outlet boundaries quickly, even in the early stage of the shearing process at shear displacements of 1 or $2 \mathrm{~mm}$. This is due to the fact that high transmissivity areas connected more rapidly when flow direction is perpendicular to the shear direction.

Comparing Figs. 9 and 10, the channel effect is more significant in the direction perpendicular to the shear direction than that with flow parallel with the shear direction.

The transmissivity field determines the velocity field, and the latter determines the travel time of the particles. The higher the transmissivity, the higher the flow velocity, and the less time it takes for the particles to travel through the fracture. This effect can be studied with the aid of breakthrough curves. A breakthrough curve shows the relation between the relative tracer concentration and time [37], and allows one to evaluate the dispersion phenomena of a tracer transport. In this study, the breakthrough curves show the relation between the percentage of particles that reach the prescribed outflow boundaries and time.

The breakthrough curves for the particle transport with the overall flow parallel with (in the $x$-direction) and perpendicular to (in the $y$-direction) the shear direction for specimens J1 were calculated and plotted in Figs. 11 and 12, respectively. Usually, there are some particles that travel faster than the bulk of particles, and a few ones that take more time to pass through the fracture. For the fast traveling particles, this happens because some particles find fast paths without passing through areas with low permeability. For slow traveling particles, the delay is due to the fact that they have to pass through more areas with low transmissivity or bypass more contact areas than other particles, thus need more time to reach the outlet boundary. Therefore the shape of breakthrough curves becomes the shapes as shown in Figs. 11 and 12. Breakthrough curves usually do not reach $100 \%$ for all cases, which means that not all particles injected at the inlet boundary can be collected at the outlet boundary and some particles are captured in areas of very slow flow velocities or areas with flow around contact areas with extremely small velocities. 
Particles start to reach the outlet boundary at the shear displacement of $2 \mathrm{~mm}$ (for flow both parallel with and perpendicular to the shear direction, see also Fig. 9 and 10) except for the flow parallel with shear direction under higher normal stress of $1.5 \mathrm{MPa}$ (Fig.11b). Particles start reaching the outlet boundaries after the shear displacement of $5 \mathrm{~mm}$ for higher normal stress of $1.5 \mathrm{MPa}$ (for flow parallel with the shear direction, Fig. 11b). In general, it can be observed that the greater the shear displacement is, the less time it takes for the particles to travel through the fracture specimens. This means that shearing makes the fracture more hydraulically conductive with higher flow velocity. The greater decrease of travel time of the particles with shear occurs generally during the early stage of shearing process with smaller shear displacements. The only exception is a major increase of mean travel time occurring at shear displacements of 15 and $18 \mathrm{~mm}$ (see Fig. 11 and Fig. 12). This is due to the fact that the specimen's shear dilation decreases slightly due to its relative smoothness and fracture aperture becomes smaller with closure. As a result, fracture becomes less conductive and flow velocity becomes smaller.

Generally, the slope of the breakthrough curves flattens with increasing shear displacement for both flow parallel with and perpendicular to the shear direction. This means that dispersivity in the fractures becomes larger and particle dispersion becomes more significant during the shearing process, since the breakthrough curves flatten with increasing dispersivity. This can be explained by the formation of new contact areas and/or localization of contact areas. More discussion will be made for this issue later after evaluating the transport properties such as Péclet number.

The effects of normal stress on the particle transport can be observed clearly by comparing Figs. $11 \mathrm{a}$ and $11 \mathrm{~b}$, and Figs. 12a and $12 \mathrm{~b}$ for the particle transport parallel with and perpendicular to the shear direction, respectively. Increasing the normal stress from $1.0 \mathrm{MPa}$ to $1.5 \mathrm{MPa}$, particles travel time increases, as a result, the breakthrough curves shift to the right. The shape of breakthrough curves also becomes flatter with increasing normal stress, which means that fracture dispersivity becomes larger under higher normal stress. This is due to the fact that fracture aperture becomes smaller and more contact areas formed inside the fracture under higher normal stress, in addition to the fact that the geometry of void space and transmissivity field becomes more complex. As a result, particle paths and travel time are more tortuous (see also comparison of figures, Fig. 9 and Fig. 10).

The mean and standard deviation of particle travel time as well as calculated Péclet numbers using Eq. (10) for the particle transport parallel with and perpendicular to the shear direction were listed in Tables 2 and 3 and plotted in Fig. 13. From Tables 2 and 3, and Figures 13a, the mean and standard deviation of particle travel time decrease with increasing shear displacement generally and the significant decreases can be observed at smaller shear displacement for all cases. The only exception can be observed for mean and standard deviation of particle travel time at the large shear displacement (15 and $18 \mathrm{~mm}$ ), where particle mean travel time increases. This is caused by the fracture closure during shear as mentioned above. The standard deviation of the particle travel time for the particle transport parallel with the shear direction drops largely at the shear displacement of $15 \mathrm{~mm}$ (Fig. 13a). This is caused by the change of particle paths (see Fig. 9) at this shear displacement, new channels appear in the middle of the specimen and particle paths become less localized. This affects the calculated Péclet numbers at the shear displacement of $15 \mathrm{~mm}$ as shown in Fig. $13 \mathrm{~b}$, with the Péclet number increased suddenly at this shear displacement. 
Generally calculated Péclet numbers decreases with increasing shear displacement, even though some exceptions were observed (Fig. 13b). To calculate Péclet numbers using Eq. (10), the standard deviation of the particle travel time plays a significant role and this is affected by the variation of the particle paths, which depends on the contact area distributions and their variation during shear.

The effects of the normal stress on the mean and standard deviation of particle travel time for both overall flow parallel with and perpendicular to the shear direction can be seen in Fig. 13a. From this figures, both mean and standard deviation of particle travel time increase with increasing normal stress. The calculated Péclet numbers, $P e$, were compared between the two cases of flow parallel with and perpendicular to the shear direction, in terms of normal stress effects on the Péclet number values as shown in Figs. 13b. The calculated Péclet numbers are generally smaller when a higher normal stress was applied. This is due to the fact that fracture will have more closure and more contact areas will form under higher normal stresses, leading to more complex void space structures and more tortuous travel paths. Therefore, the standard deviation becomes larger, and according to Eq. (10), Péclet numbers becomes smaller. Similar results were also reported in $[4,6]$. Their results show that the Péclet number increases (accompanying with the decrease of dispersivity) with a decrease of the normal stress and an increase of surface separation. In their works, the effect of shear displacement on the particle transport was not considered.

The Péclet numbers are always smaller for flow perpendicular to the shear direction than those for the flow parallel with shear direction. The Péclet numbers for flow parallel with the shear direction changes more drastically (from 37 to 3 ) during shear than the ones for flow perpendicular to the shear direction. The larger Péclet number with flow parallel with the shear direction means that advective transport is more dominant in this direction.

\section{Discussions and concluding remarks}

In the present study, the fluid flow and particle transport in rock fracture replicas during shear under different normal stress conditions were simulated using the COMSOL Multiphysics code of FEM, with a special algorism for contact areas for fluid flow and streamline particle tracking, considering evolutions of aperture and transmissivity fields during shear under different normal loads, obtained from real coupled shear-flow tests of fracture specimens of realistic surface roughness features. The numerical prediction results compared well with the results obtained from the laboratory coupled shear-flow tests for the fluid flow parallel with the shear displacement, and particle transport properties were predicted by numerical simulations. From the obtained flow velocity fields, the particle transport was predicted by the streamline particle tracking method with calculated flow velocity fields (vectors) from the flow simulations, obtaining results such as flow velocity profiles, total flow rates, particle travel time, breakthrough curves and the Péclet number, $P e$, respectively.

Besides the above summary, a few outstanding issues need to be further discussed.

a) Technical difficulties of measuring evolutions of aperture during shear

The accurate knowledge of aperture evolution under normal loading during shear is important for the development of coupled hydro-mechanical constitutive models for rock fractures. To get accurate aperture values during shear, direct measurement is desirable but not possible in 
practice in laboratory tests at present. The most common way to obtain the mean aperture in numerical modeling is to calculate the distance of superimposed two rough surfaces in the direction perpendicular to the nominal fracture plane, which is adopted in this study, and back-calculation using measured flow rate in tests assuming validity of the cubic law. However, some assumptions are always required to determine the initial position of rough surfaces corresponding to the samples' in situ stress conditions, to quantify the local aperture distribution, and to estimate relocation errors. More accurate measurement of relocation errors at the start and quantification of tilting effects during shear are important for more accurate numerical predictions.

b) Validity of Reynolds equation (the cubic law)

The Navier-Stokes equations have been solved using FEM in real fracture geometry, considering non-linear regimes of fluid flow in rock fractures, with results compared to experiments, as reported in [38]. The Reynolds equation, on the other hand, is more commonly used for the flow in fractures for its simplicity, as demonstrated by many publications, under certain conditions of hydraulic gradient, aperture, fluid velocity, etc., depending on the Reynolds number of the flow fields. We used the Reynolds equation for simplicity in this work since effects of normal stress and shear displacement on fluid flow in fractures are the causes of first order variations and are therefore the main concern, and believed that the Reynolds equation could be acceptable for the current studies. To check whether our assumption is valid, we calculated the Reynolds numbers from the measured flow data during the tests. The Reynolds number for flow through single rock fractures is defined as

$$
\mathrm{Re}=\frac{\rho Q}{\mu W}\left(=\frac{\rho U \bar{b}}{\mu}\right),
$$

where $Q$ is the measured bulk flow rate through the fracture, $W$ is the fracture sample width, $\bar{b}$ is mean fracture aperture, respectively. The product $(\bar{b} \cdot W)$ represents the average cross-sectional area and $U$ is characteristic fluid velocity (such as the mean flow velocity using aperture-average). The calculated Reynolds numbers for each shear displacement from Eq. (11) are shown in Table 4.

According to Olsson [39], $\operatorname{Re}<300$ and $\operatorname{Re}<2300$ are the upper limits for laminar flow for rough and smooth fractures, respectively. The maximum value of calculated Reynolds number from the measured flow rates during the laboratory tests are 67 and 54 at shear displacement of $18 \mathrm{~mm}$ under the normal stress of 1.0 MPa and 1.5 MPa, respectively, in our study. The calculated Reynolds numbers in this study therefore satisfy the requirements for laminar steady state flows, as we assumed. Therefore, use of Reynolds equation for solving the flow can be accepted.

c) Special treatments for contact area

In this study, contact areas were treated with zero aperture and no flux boundaries were applied along the contact area. This contact algorithm is an important link for realistic simulations of couplings between stress and fluid flow in fractures with shear and under normal loading. The results show that such special treatment of contact areas can simulate more realistic behavior of flow fields in fractures that is important for particle transport simulations [29-30]. 
d) Asperity damage and gouge materials

The asperity degradation/damage and generation of gouge materials cannot be measured at asperity scale directly during shear tests, due to the same technical difficulty as the determination of aperture field during shear. However, they may have significant effects on fluid flow in rock fractures. Although gouge generation is ignorable in the presented work, the deformation and damage of the asperities at contacts may still play an important role in the discrepancies between the measured and simulated flow rate values. More development in numerical modelling with functions of stress, deformation and damage analyses are needed to improve the capacity of more reliable numerical modelling tools. On the other hand, development of more advanced experimental techniques for quantitative real-time measurement of initial conditions and evolution of aperture and surface roughness during shear with normal loading, in conjunction with fluid flow, however, is more important to deepen our scientific understanding and provide more reliable data for model development and validations.

e) The applicability of the particle tracking method

The streamline particle tracking is applicable when advective transport is dominant over diffusion. The particle movement in the aperture direction caused by diffusion, $\Delta x$ can be calculated from the following equation.

$$
\Delta x \approx \sqrt{D_{w} \cdot t}
$$

where $D_{w}$ is diffusivity in water $\left(=10^{-9} \mathrm{~m}^{2} / \mathrm{s}\right)$ and $t$ is time.

From the results as listed in Tables 2 and 3, the maximum mean particle travel time for advective transport parallel with and perpendicular to the shear direction is $772 \mathrm{sec}$ (for J1-1) and $17 \mathrm{sec}$ (for J1-2), respectively. From Eq. (12), the distances of particle movement caused by diffusion are $0.88 \mathrm{~mm}$ and $0.13 \mathrm{~mm}$, respectively. Comparing with the length of fracture, $200 \mathrm{~mm}$ and $100 \mathrm{~mm}$, the particle movement caused by diffusion is negligible. Therefore the particle tracking method is applicable in this study.

f) Particle injection methods - the flow rate-weighted particle injection method

In this study, the flow rate-weighted particle injection method was used. This injection method is more realistic because higher flow rate attracts more particles along the inlet boundary. However, evenly distributed particle numbers along the inlet were also used in some literature without evaluating its effect on the evaluated transport properties, such as breakthrough curves, dispersivity and Péclet number [40-42]. This issue is extensively investigated in the previous work by the authors [34].

\section{Acknowledgement}

The authors thank the Swedish Nuclear Power Inspectorate (SKI) for the financial support for the first author's Ph.D studies at Royal Institute of Technology (KTH), Stockholm, Sweden.

\section{References}

[1] Brown SR, Caprihan A and Hardy R. Experimental observation of fluid flow channels in a single fracture. J Geophys Res, 1998; 103(B3): 5125-5132. 
[2] Detwiler RL, Pringle SE and Glass RJ. Measurement of fracture aperture fields using transmitted light: An evaluation of measurement errors and their influence on simulations of flow and transport through a single fracture. Water Resour Res, 1999; 35(9): 2605-2617.

[3] Renshaw CE, Dadakis JS and Brown SR. Measuring fracture apertures: A comparison of methods. Geophys Res Lett, 2000; 27(2); 289-292.

[4] Thompson ME. Numerical simulation of solute transport in rough fractures. J Geophys Res, 1991; 96(B3): 4157-4166.

[5] Plouraboue F, Kurowski P, Boffa JM, Hulin JP and Roux S. Experimental study of the transport properties of rough self-affine fractures. J Contam Hydrol, 2000; 46: 295-318.

[6] Jeong W and Song J. Numerical investigations for flow and transport in a rough fracture with hydromechanical effect. Energy Sources, 2005; 27: 997-1011.

[7] Auradou H, Drazer G, Hulin JP and Koplik J. Permeaqbility anisotropy induced by the shear displacement of rough fracture walls. Water Resour Res, 2005; 41: W09423, doi: 10.1029/2005WR003938.

[8] Auradou H, Drazer G, Boschan A, Hulin JP and Koplik J. Flow channeling in a single fracture induced by shear displacement. Geothermics, 2006; 35: 576-588.

[9] Neretnieks I, Eriksen T and Tähtinen P. Tracer movement in a single fracture in granitic rock: Some experimental results and their interpretation. Water Resour Res, 1982; 18(4): 849-858.

[10] Tsang YW, Tsang CF, Neretnieks I and Moreno L. Flow and tracer transport in fractured media: A valuable aperture channel model and its properties. Water Resour Res, 1988; 24(12): 2049-2060.

[11] Moreno L, Tsang YW, Tsang CF and Neretnieks I. Some anomalous features of flow and solute transport arising from fracture variability. Water Resour Res, 1990; 26(10): 2377-2391.

[12] Thompson ME and Brown SR. The effect of anisotropic surface roughness on flow and transport on fractures. J Geophys Res, 1991; 96(B13): 21,923-21,932.

[13] Wendland E and Himmelsbach T. Transport simulation with stochastic aperture for a single fracture - comparison with a laboratory experiment. Advance in Water Resources, 2002; 25(1): 19-33.

[14] Cvetkovic V. Mass arrival of reactive solute in single fractures. Water Resour Res, 1991; 27(2): 177-183.

[15] Kennedy CA and Lennox WC. A control volume of solute transport in a single fracture. Water Resour Res, 1995; 31(2): 313-322.

[16] Cvetkovic V, Selroos JO and Cheng H. Transport of reactive tracers in rock fractures. J Fluid Mech. 1999; 378(10): 335-356.

[17] Yeo IW, De Freitas MH and Zimmerman RW. Effect of shear displacement on the aperture and permeability of rock. Int J Rock Mech Min Sci, 1998; 35: 1051-70.

[18] Lespinasse $M$ and Sausse J. Quantification of fluid flow: hydro-mechanical behaviour of different natural rough fractures. J Geochemical Exploration, 2000; 60-70: 483-486.

[19] Koyama T, Fardin N, Jing L and Stephansson O. Numerical simulation of shear induced flow anisotropy and scale dependent aperture and transmissivity evolutions of fracture replicas. Int J Rock Mech Min Sci, 2006; 43(1): 89-106.

[20] Matsuki K, Chida Y, Sakaguchi K and Glover PWJ. Size effect on aperture and permeability of a fracture as estimated in large synthetic fractures. Int J Rock Mech Min Sci, 2006; 43(5): 726-755.

[21] Li B, Jiang Y, Saho R, Tasaku Y and Tanabashi Y. An investigation of hydromechanical behaviour and transportability of rock joints. In: Rock Mechanics in Underground 
Construction, Proc of the 4th Asian Rock Mech Symp, eds. Leung CF Y and Zhou YX, World Scientific, 2006, pp. 321.

[22] Li B, Jiang Y, Koyama T, Jing L and Tanabashi Y. Experimental study on hydro-mechanical behaviour of rock joints by using parallel-plates model containing contact area and artificial fractures. Int $J$ Rock Mech Min Sci, 2007, doi:10.1016/j.ijrmms.2007.06.004 (in press).

[23] Jiang Y, Xiao J, Tanabashi Y and Mizokami T. Development of an automated servo-controlled direct shear apparatus applying a constant normal stiffness condition. Int J Rock Mech Min Sci, 2004; 41(2): 275-286.

[24] Jiang Y, Li B and Tanabashi Y. Estimating the relation between surface roughness and mechanical properties of rock joints. Int J Rock Mech Min Sci, 2006; 43(6): 837-846.

[25] Esaki T, Du S, Mitani Y, Ikusada K and Jing L. Development of a shear-flow test apparatus and determination of coupled properties for a single rock joint. Int $\mathrm{J}$ Rock Mech Min Sci 1999; 36: 641-50.

[26] Bandis S, Lumsden C and Barton N. Fundamentals of rock joint deformation. Int J Rock Mech Min Sci Geomech Abstr, 1983, 20(6), 249-268.

[27] Zimmerman RW and Bodvarsson GS. Hydraulic conductivity of rock fractures. Transp Porous Media, 1996; 23: 1-30.

[28] COMSOL AB. COMSOL Multiphysics Ver.3.3, Stockholm, 2006. Home page: http://www.comsol.se

[29] Koyama T, Li B, Jiang Y, and Jing L. Numerical modeling of fluid flow tests in a rock fracture with a special algorithm for contact areas. Manuscript submitted to Computers and Geotechniques, January, 2007

[30] Koyama T and Jing L. Fluid flow and tracer transport simulations for rock fractures under normal loading and shear displacement. In: Proc of the 11th Int Congr Rock Mech (ISRM 2007), Lisbon, Portugal, 9-13 July, 2007, pp. 47-50.

[31] Zimmerman RW, Chen DW and Cook NGW. The effect of contact area on the permeability of fractures. J Hydrology, 1992; 139: 79-96.

[32] Neuman SP. A Eulerian-Lagrangian numerical scheme for the dispersion-convection equation using conjugate space-time grid. J Comp Phys, 1981; 41: 270-294.

[33] Neuman SP. Adaptive Eulerian-Lagrangian finite element method for advectiondispersion. Int J Numer Meth Eng, 1984; 20: 321-337.

[34] Koyama T. Numerical modeling of fluid flow and particle transport in rock fractures during shear. Licentiate Thesis, Royal Institute of Technology (KTH), Stockholm, Sweden, 2005. ISBN91-7178-232-1. $230 \mathrm{p}$.

[35] Levenspiel O. Chemical Reaction Engineering. 3rd edn. Wiley, New York, 1999.

[36] Tsang YW and Tsang CF. Channels model of flow through fractured media. Water Resour Res, 1987; 23(3): 467-479.

[37] Bear J. Dynamics of fluid in porous media. 1st ed. Elsevier, 1972; Dover, Toronto, 1988, pp. 580-585.

[38] Zimmerman RW, Al-Yaarubi A, Pain CC, and Grattoni CA. Non-linear regimes of fluid flow in rock fractures. Int J Rock Mech Min Sci, 2004; 41(3): 384-384.

[39] Olsson R. Mechanical and hydromechanical behaviour of haed rock joints - a laboratory study. Ph. D Thesis, Chalmers university of Technology, Göteborg, Sweden, 1998, p197.

[40] Grindrod P and Lee AJ. Colloid migration in symmetrical non-uniform fractures: particle tracking in three dimensions. J Contam Hydrol, 1997; 27: 157-175.

[41] James SC and Chrysikopoulos CV. Transport of polydisperse colloids in a saturated fracture with spatially variable aperture, Water Resour Res, 2000; 36(6): 1457-1465. 
[42] Boutt DF, Grasselli G, Fredrich JT, Cook BK and Williams JR. Trapping zone: The effect of fracture roughness on the directional anisotropy of fluid flow and colloid transport in a single fracture. Geophys Res Lett, 2006, 33, L21402, doi: 10.1029/2006GL027275. 
Table 1. Comparison of the flow rates at the outlet between laboratory experiments and numerical simulation for fracture specimen, J1 under normal stresses of 1MPa (J1-1) and 1.5 MPa (J1-2).

(unit: $\mathrm{m}^{3} / \mathrm{sec}$ )

\begin{tabular}{crrrr}
\hline Shear disp. & \multicolumn{2}{c}{ J1-1 (CNL, 1.0 MPa) } & \multicolumn{2}{c}{ J1-2 (CNL, 1.5 MPa) } \\
\cline { 2 - 5 } mm & Experiments & Simulation & Experiments & Simulation \\
\hline 0 & 0 & - & $1.81 \mathrm{e}-08$ & - \\
1 & 0 & 0 & $1.44 \mathrm{e}-08$ & 0 \\
2 & $8.13 \mathrm{e}-09$ & $3.31 \mathrm{e}-09$ & $1.34 \mathrm{e}-08$ & 0 \\
3 & $1.73 \mathrm{e}-07$ & $5.85 \mathrm{e}-08$ & $1.30 \mathrm{e}-07$ & $2.02 \mathrm{e}-10$ \\
5 & $9.44 \mathrm{e}-07$ & $4.73 \mathrm{e}-07$ & $1.39 \mathrm{e}-06$ & $8.85 \mathrm{e}-08$ \\
7 & $3.00 \mathrm{e}-06$ & $9.48 \mathrm{e}-07$ & $2.37 \mathrm{e}-06$ & $1.38 \mathrm{e}-07$ \\
10 & $7.00 \mathrm{e}-06$ & $1.67 \mathrm{e}-06$ & $4.30 \mathrm{e}-06$ & $4.74 \mathrm{e}-07$ \\
15 & $8.61 \mathrm{e}-06$ & $1.74 \mathrm{e}-06$ & $5.93 \mathrm{e}-06$ & $4.65 \mathrm{e}-07$ \\
18 & $8.81 \mathrm{e}-06$ & $1.14 \mathrm{e}-06$ & $7.14 \mathrm{e}-06$ & $3.10 \mathrm{e}-07$ \\
\hline
\end{tabular}


Table 2. Mean and standard deviation of particle travel time and calculated Péclet numbers from Eq. (10) for fracture sample J1 under normal stresses of 1.0 MPa, (J1-1) and 1.5 MPa (J1-2) at different shear displacement for the particle movement parallel with the shear direction.

\begin{tabular}{ccccccccc}
\hline & $1 \mathrm{~mm}$ & $2 \mathrm{~mm}$ & $3 \mathrm{~mm}$ & $5 \mathrm{~mm}$ & $7 \mathrm{~mm}$ & $10 \mathrm{~mm}$ & $15 \mathrm{~mm}$ & $18 \mathrm{~mm}$ \\
\hline \hline Mean_J1-1 & - & 772.15 & 66.98 & 12.87 & 7.43 & 4.73 & 5.29 & 7.80 \\
Mean_J1-2 & - & - & - & 56.91 & 36.64 & 15.72 & 16.20 & 25.87 \\
Std.dev_J1-1 & - & 181.04 & 31.70 & 3.85 & 3.03 & 2.74 & 1.53 & 3.08 \\
Std.dev_J1-2 & - & - & - & 20.12 & 12.68 & 11.15 & 5.48 & 20.28 \\
Pe_J1-1 & - & 36.38 & 8.93 & 22.34 & 12.06 & 5.94 & 23.98 & 12.83 \\
Pe_J1-2 & - & - & - & 16.00 & 16.71 & 3.97 & 17.47 & 3.26 \\
\hline
\end{tabular}

Table 3. Mean and standard deviation of particle travel time and calculated Péclet numbers from Eq. (10) for fracture sample J1 under normal stresses of 1.0 MPa (J1-1) and 1.5 MPa (J1-2) at different shear displacement for the particle movement perpendicular to the shear direction.

(unit: sec)

\begin{tabular}{ccccccccc}
\hline & $1 \mathrm{~mm}$ & $2 \mathrm{~mm}$ & $3 \mathrm{~mm}$ & $5 \mathrm{~mm}$ & $7 \mathrm{~mm}$ & $10 \mathrm{~mm}$ & $15 \mathrm{~mm}$ & $18 \mathrm{~mm}$ \\
\hline \hline Mean_J1-1 & - & 12.90 & 4.25 & 1.14 & 0.72 & 0.46 & 0.43 & 0.54 \\
Mean_J1-2 & - & $124.42^{*}$ & 17.11 & 2.25 & 1.51 & 0.84 & 0.70 & 0.67 \\
Std.dev_J1-1 & - & 9.16 & 2.79 & 0.70 & 0.52 & 0.33 & 0.37 & 0.86 \\
Std.dev_J1-2 & - & $0^{*}$ & 9.30 & 1.95 & 1.68 & 0.95 & 0.91 & 1.13 \\
Pe_J1-1 & - & 3.97 & 4.67 & 5.36 & 3.88 & 3.94 & 2.71 & 0.79 \\
Pe_J1-2 & - & $-{ }^{*}$ & 6.77 & 2.67 & 1.60 & 1.58 & 1.20 & 0.70 \\
\hline
\end{tabular}

* very high Pe caused by the calculation from mean and standard deviation of particle travel time using too small number of particles collected at outlet and will not be plotted in Fig. 13. 
Table 4. Calculated Reynolds numbers, Re of the flow during the tests

\begin{tabular}{ccc}
\hline Shear disp. mm & J1-1 (CNL, 1.0 MPa) & J1-2 (CNL, 1.5 MPa) \\
\hline 0 & 0 & 0.1389 \\
1 & 0 & 0.1105 \\
2 & 0.0622 & 0.1026 \\
3 & 1.322 & 0.9907 \\
5 & 7.220 & 10.62 \\
7 & 22.98 & 18.14 \\
10 & 53.54 & 32.86 \\
15 & 65.84 & 45.36 \\
18 & 67.39 & 54.63 \\
\hline
\end{tabular}




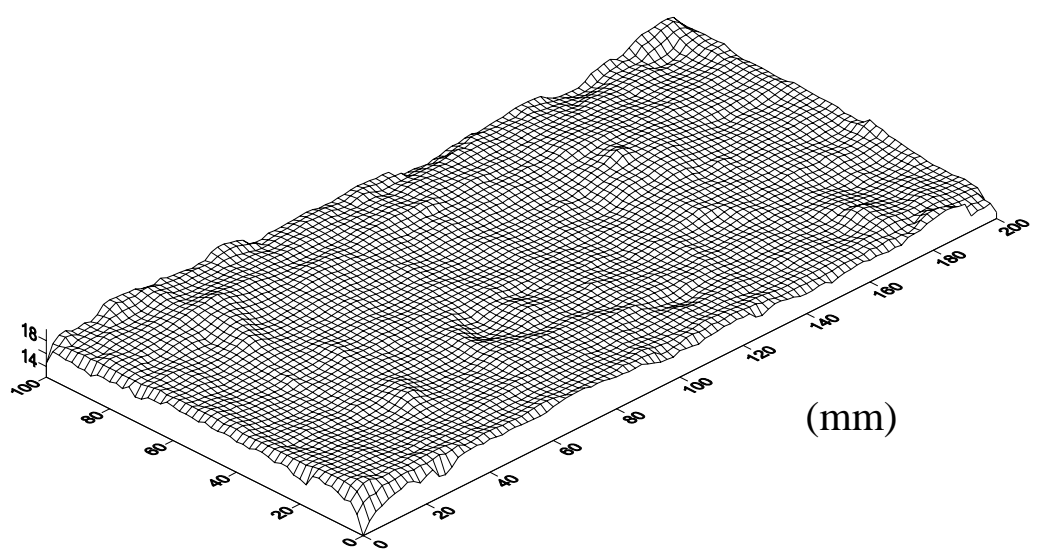

Figure 1. 3-D models of fracture specimen obtained from a natural rock fracture surface, J1 based on the measured topographical data. It should be noted that the resolution of the figures was reduced up to mesh size of $2 \mathrm{~mm}$. 


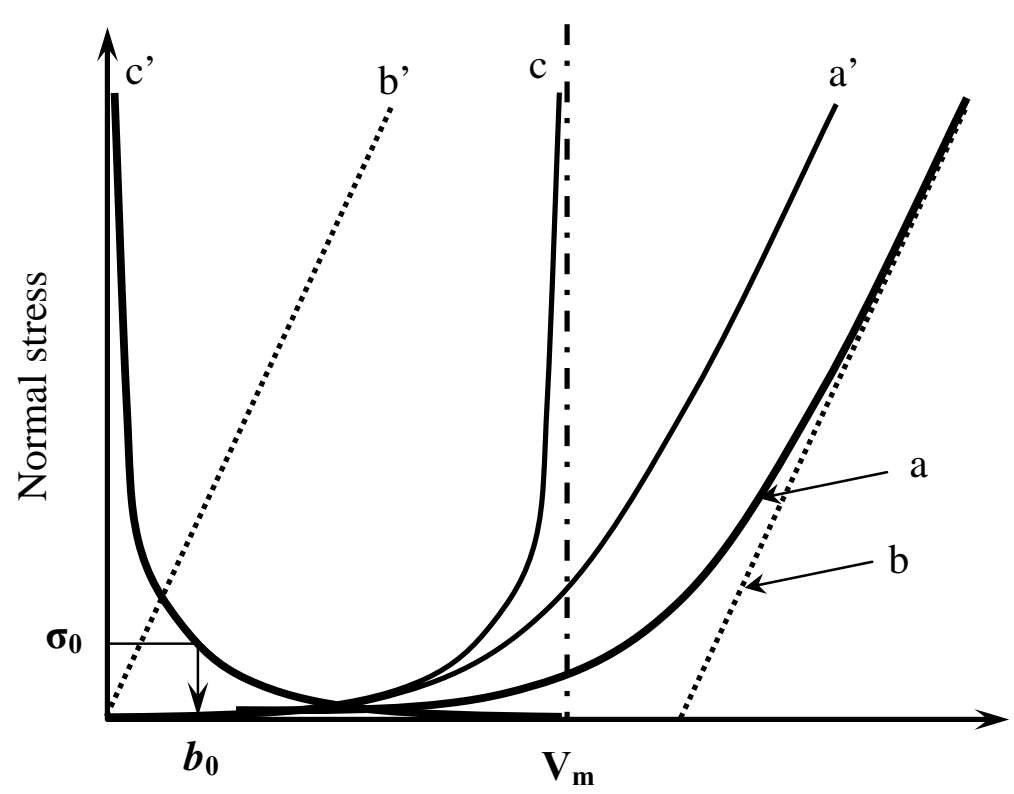

Normal displacement

a: Test result (normal cyclic loading test, after a few cycle)

b: Elastic deformation of intact part

a': shifted curve a to the origin of the coordinate axes

b': shifted curve $b$ to the origin of the coordinate axes

c: fracture deformation (a'-b')

$c^{\prime}$ : mirror image of curve $c$

$\mathrm{V}_{\mathrm{m}}$ : maximum closure, which is assumed to be equal to mechanical aperture at zero stress $\sigma_{0}$ : initial normal stress

$b_{0}$ : initial normal aperture

Figure 2. Schematic drawing for the relation between normal stress and normal displacement of the fracture and the evaluation method for initial apertures at a certain initial normal stresses. 


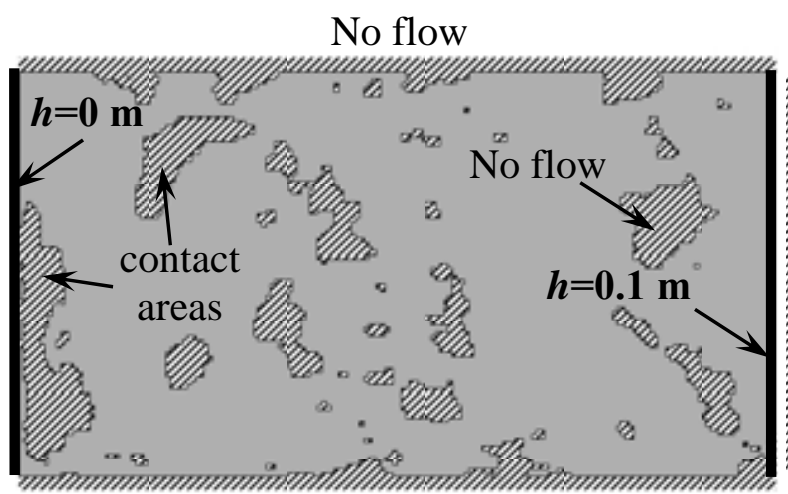

No flow

a)

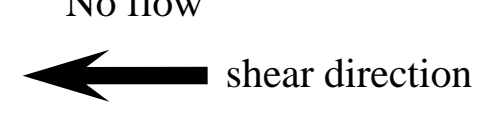

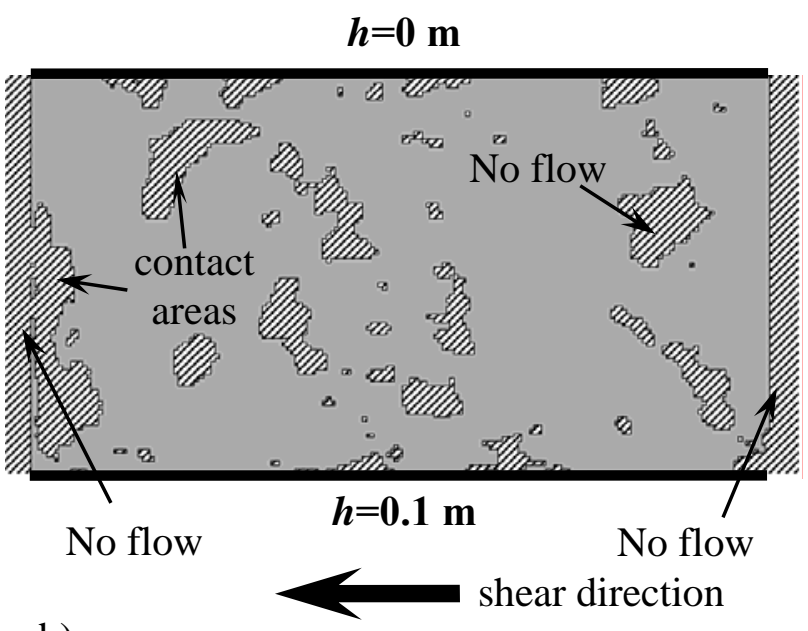

b)

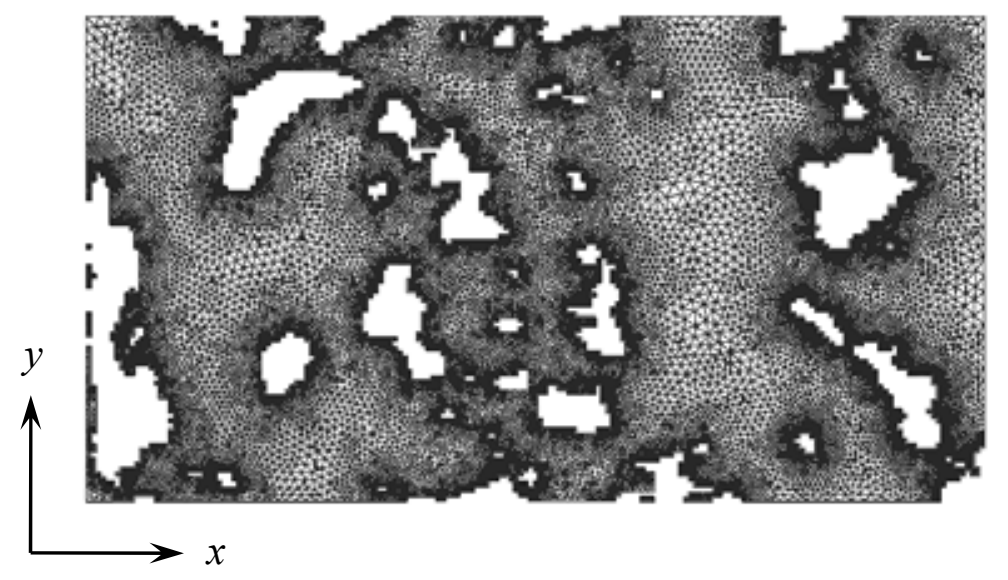

c)

Figure 3. Boundary conditions for the flow model, a) parallel with and b) perpendicular to the shear displacement, and c) a typical FEM mesh. 


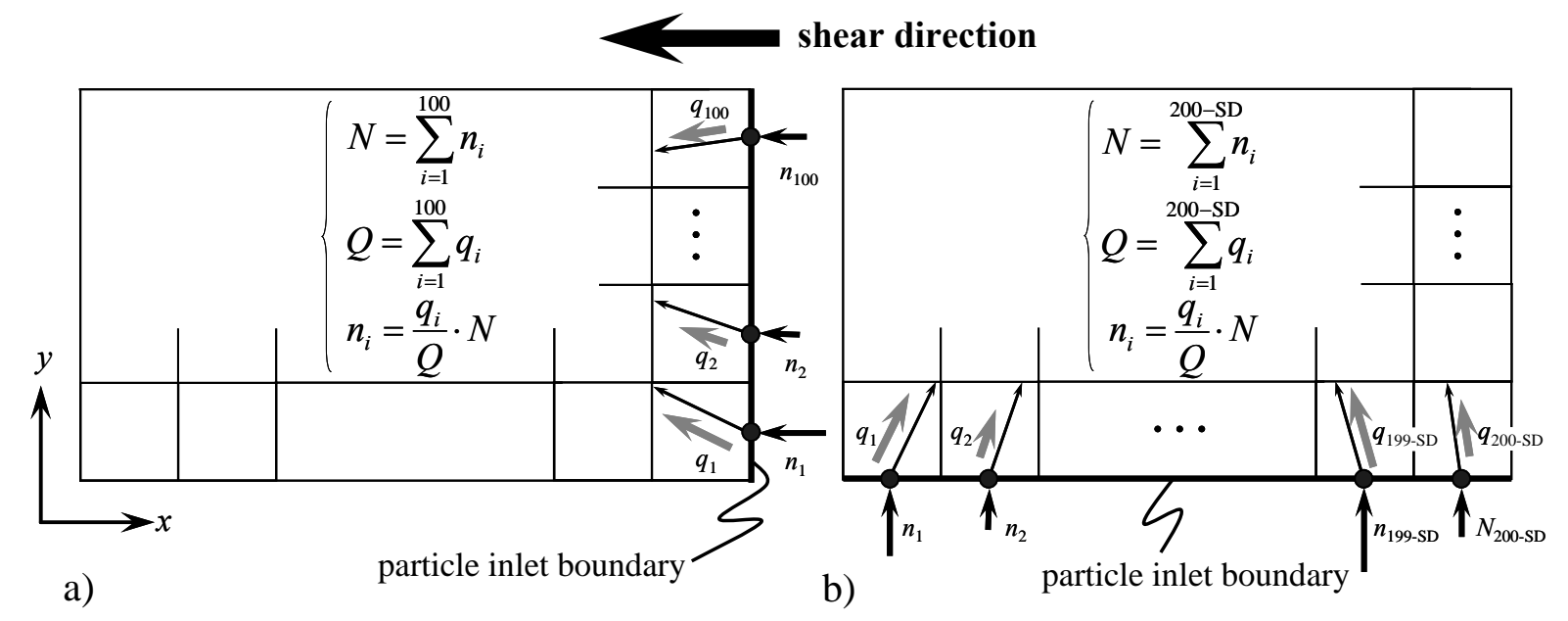

Figure 4. Calculation method for the number of particles that were introduced at the inlet boundaries for the particle transport: a) parallel with and b) perpendicular to the shear displacement. It should be noted that the number of injection points decreases during shear for flow perpendicular to the shear direction. The SD in the right figure means shear displacement, which changes from 1 to $18 \mathrm{~mm}$. 

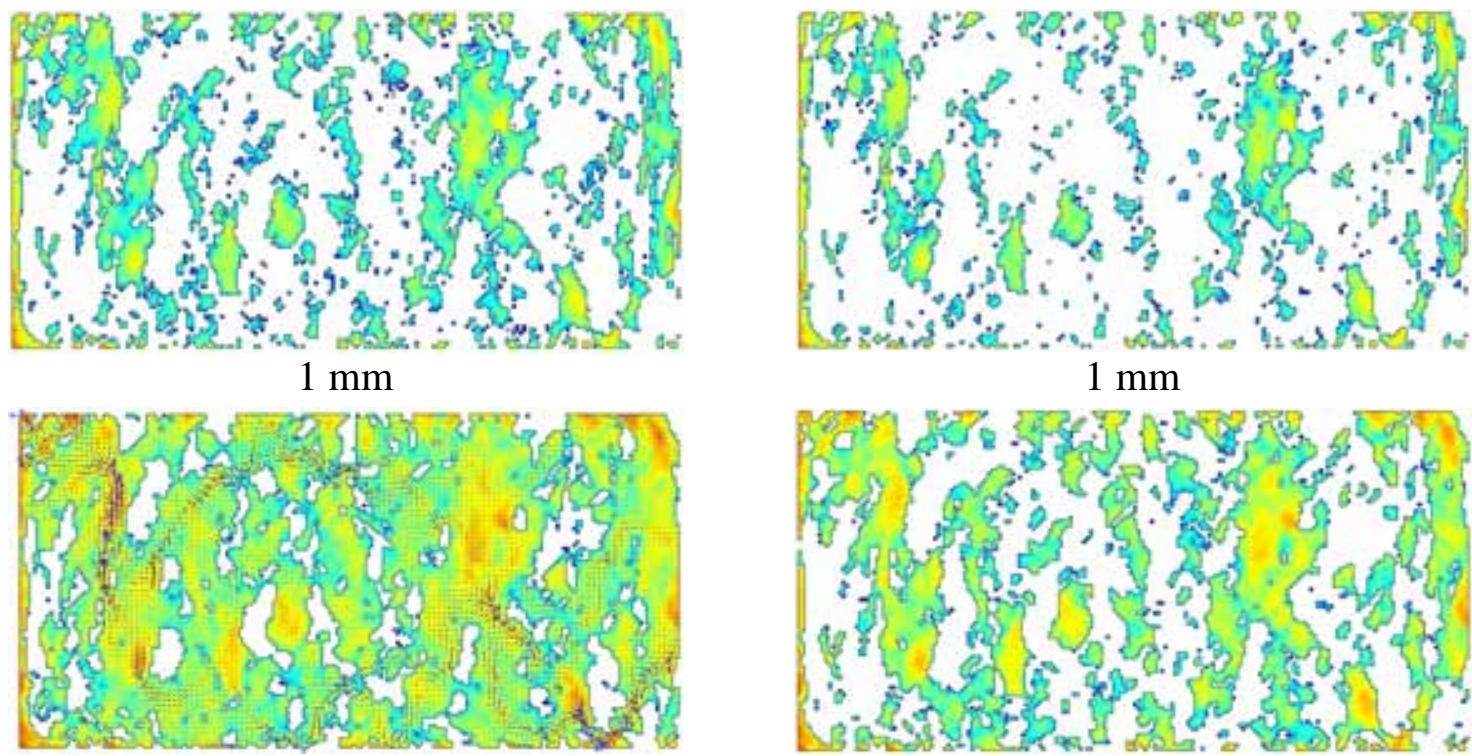

$2 \mathrm{~mm}$

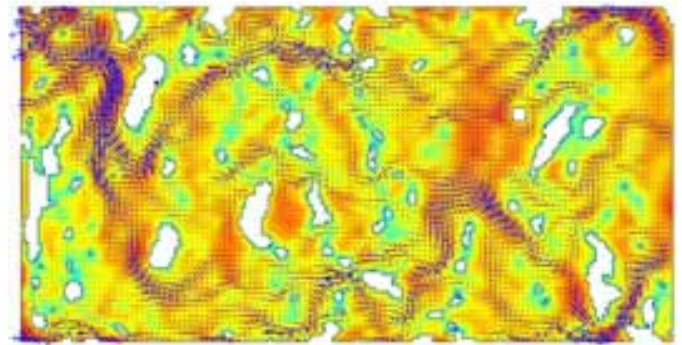

$5 \mathrm{~mm}$

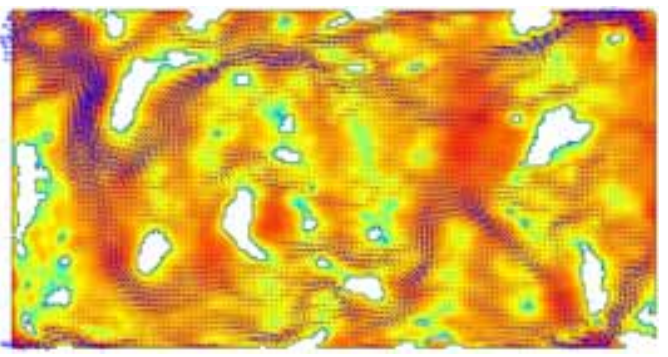

$10 \mathrm{~mm}$

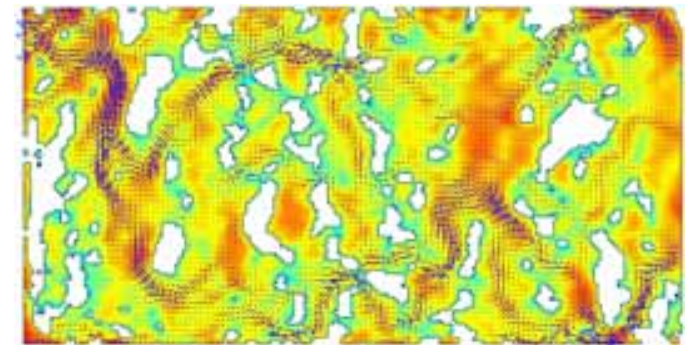

$5 \mathrm{~mm}$

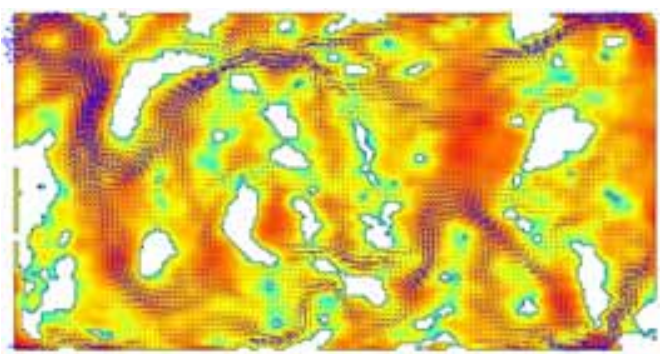

$10 \mathrm{~mm}$
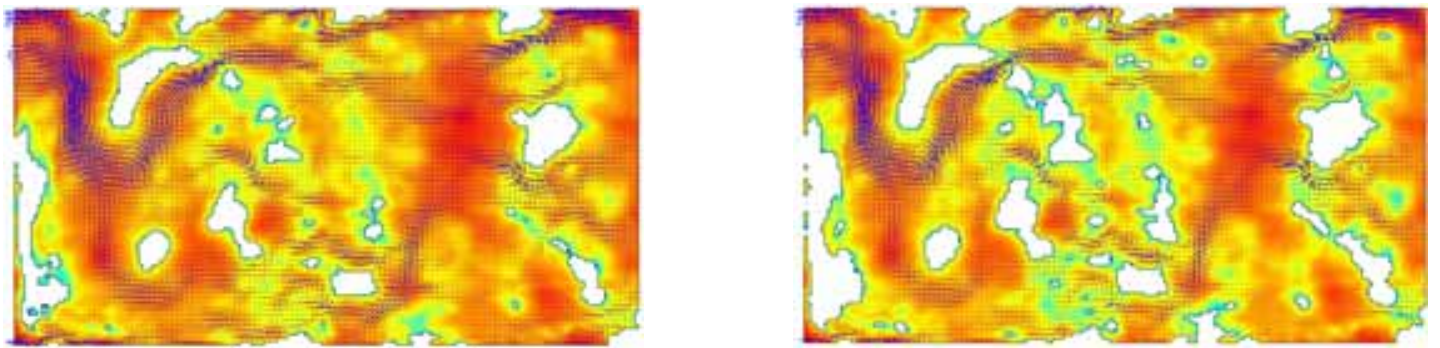

a)

$15 \mathrm{~mm}$

b)

$15 \mathrm{~mm}$

shear direction

Min: -13

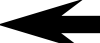

Max: 0

$\begin{array}{lllllll}-12 & -10 & -8 & -6 & -4 & -2 & 0\end{array}$

Figure 5. Flow velocity fields for the fluid flow parallel with shear direction with transmissivity evolutions at different shear displacement of 1, 2, 5 and $10 \mathrm{~mm}$ for fracture sample, J1 under normal stresses, a) J1-1 (CNL, 1.0 MPa) and b) J1-2 (CNL, 1.5MPa). It should be noted that the white 'islands' in the fracture samples present contact areas and the legend shows the order of magnitude of the fracture transmissivity $\left(\mathrm{m}^{2} / \mathrm{sec}\right)$. 


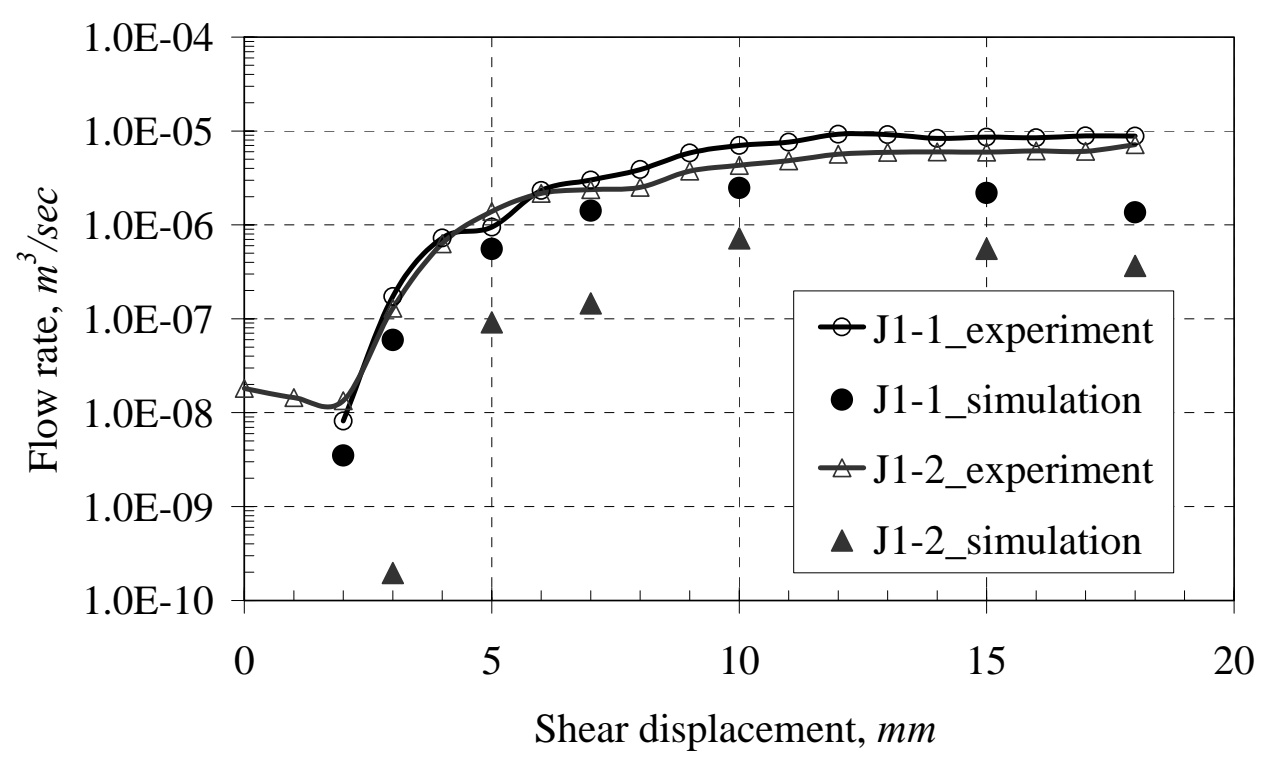

Figure 6. Comparison of the flow rate at the outlet between laboratory experiment and numerical simulation for fracture sample J1 under two normal stresses, a) 1.0 MPa (J1-1) and b) $1.5 \mathrm{MPa}(\mathrm{J} 1-2)$. It should be noted that zero flow rate value can not be plotted in the log scale, which is used at the initial shear stages during numerical prediction. 

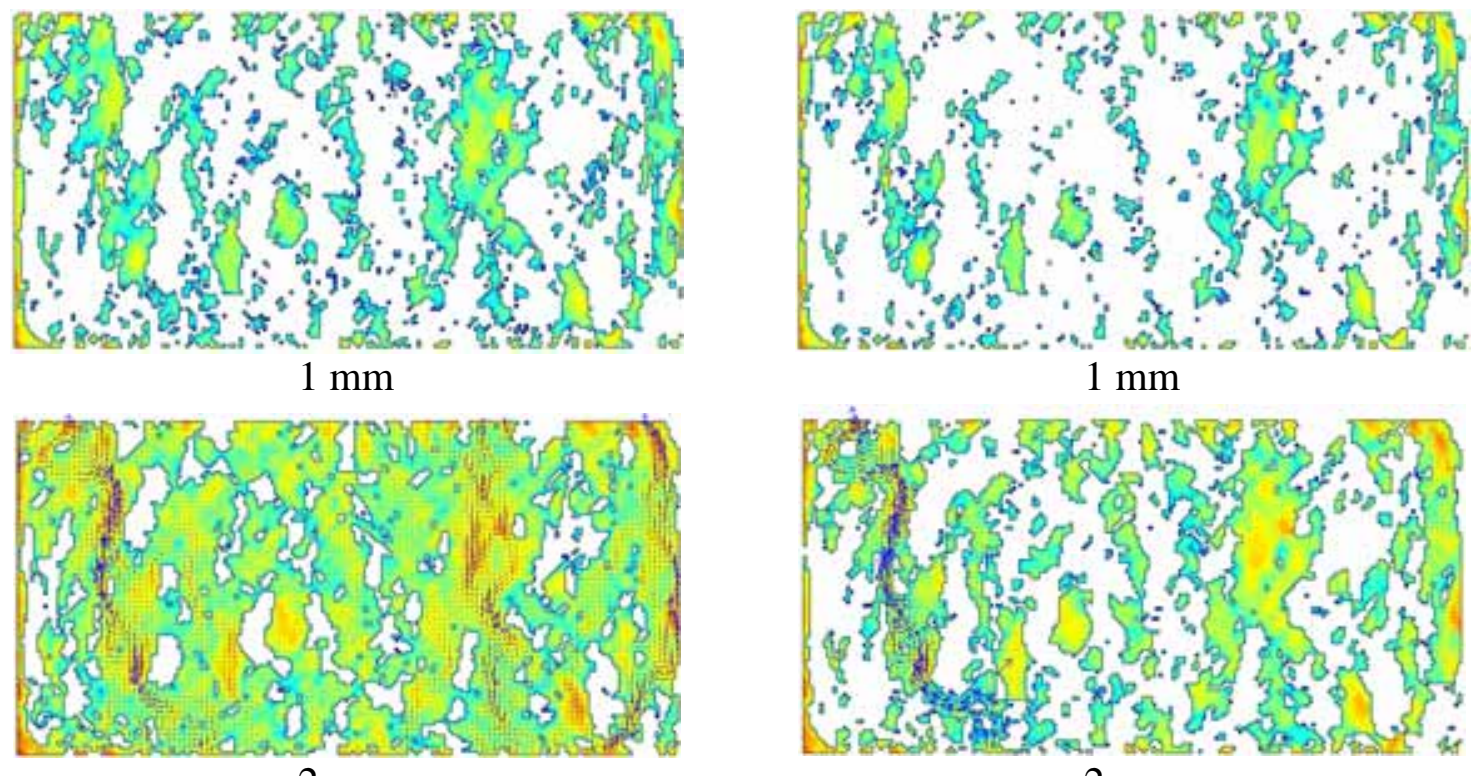

\section{$2 \mathrm{~mm}$}

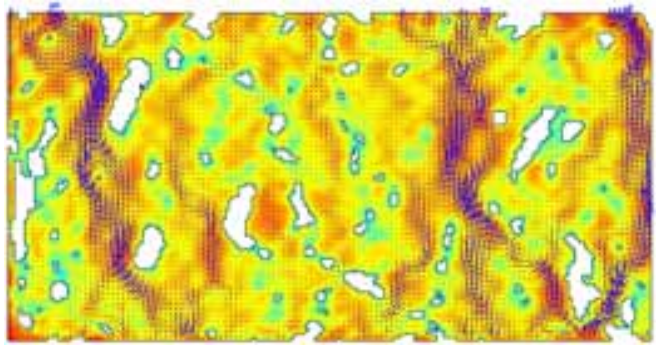

$5 \mathrm{~mm}$

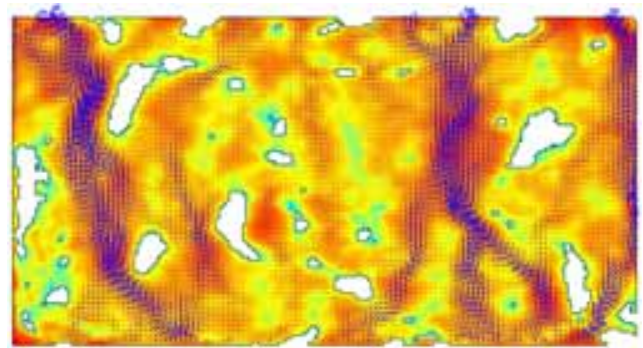

$10 \mathrm{~mm}$

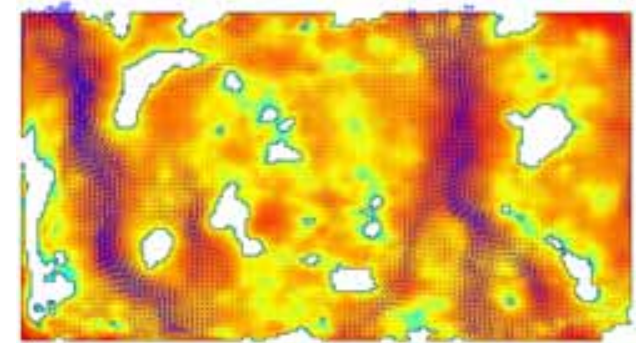

a)

$15 \mathrm{~mm}$

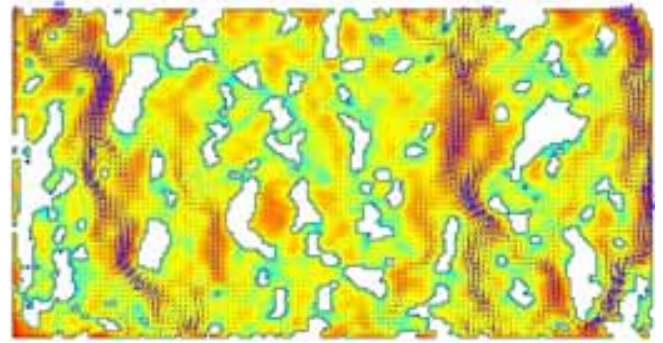

$5 \mathrm{~mm}$

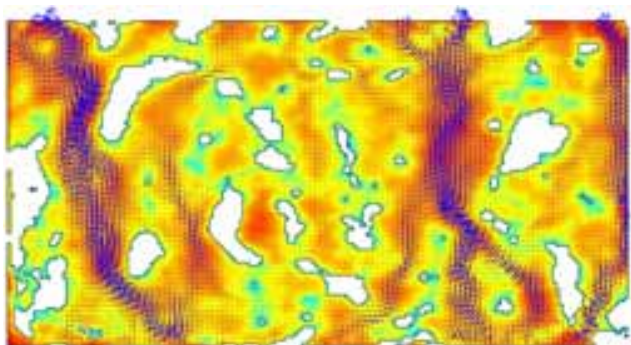

$10 \mathrm{~mm}$

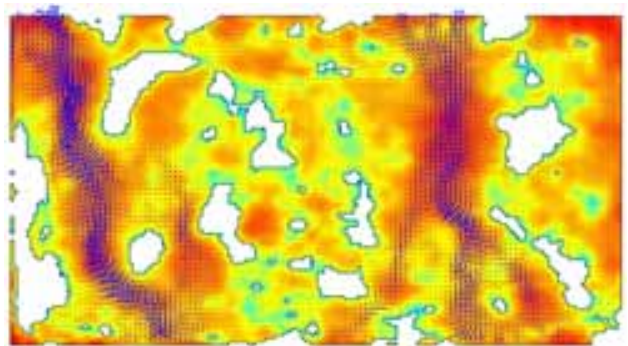

b)

$15 \mathrm{~mm}$

shear direction

Min: -13

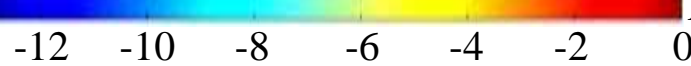

Max: 0

Figure 7. Flow velocity fields for the fluid flow perpendicular to the shear direction with transmissivity evolutions at different shear displacement of 1, 2, 5, 10 and $15 \mathrm{~mm}$ for fracture sample, J1 under two normal stresses, a) J1-1 (CNL, 1.0 MPa) and b) J1-2 (CNL, $1.5 \mathrm{MPa}$ ). It should be noted that the white 'islands' in the fracture samples present contact areas and the legend shows the order of magnitude of the fracture transmissivity $\left(\mathrm{m}^{2} / \mathrm{sec}\right)$. 


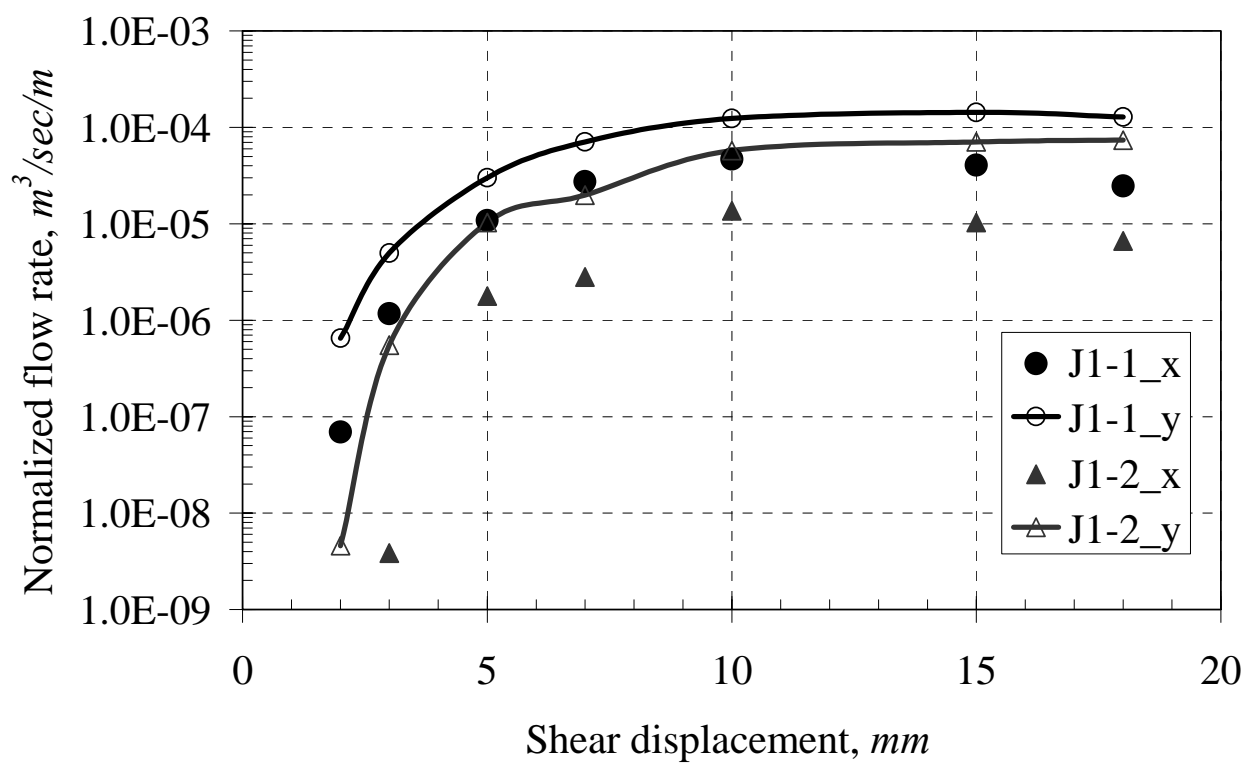

Figure 8. Comparison of the normalized flow rates at the outlet for fracture specimen, J1 with normal stress of 1.0 MPa (J1-1) and 1.5 MPa (J1-2) between the overall flows in the direction parallel with ( $x$-direction) and perpendicular to ( $y$-direction) the shear direction. It should be noted that zero flow rate value can not be plotted in the log scale, which is used at the initial shear stages for numerical prediction.. 

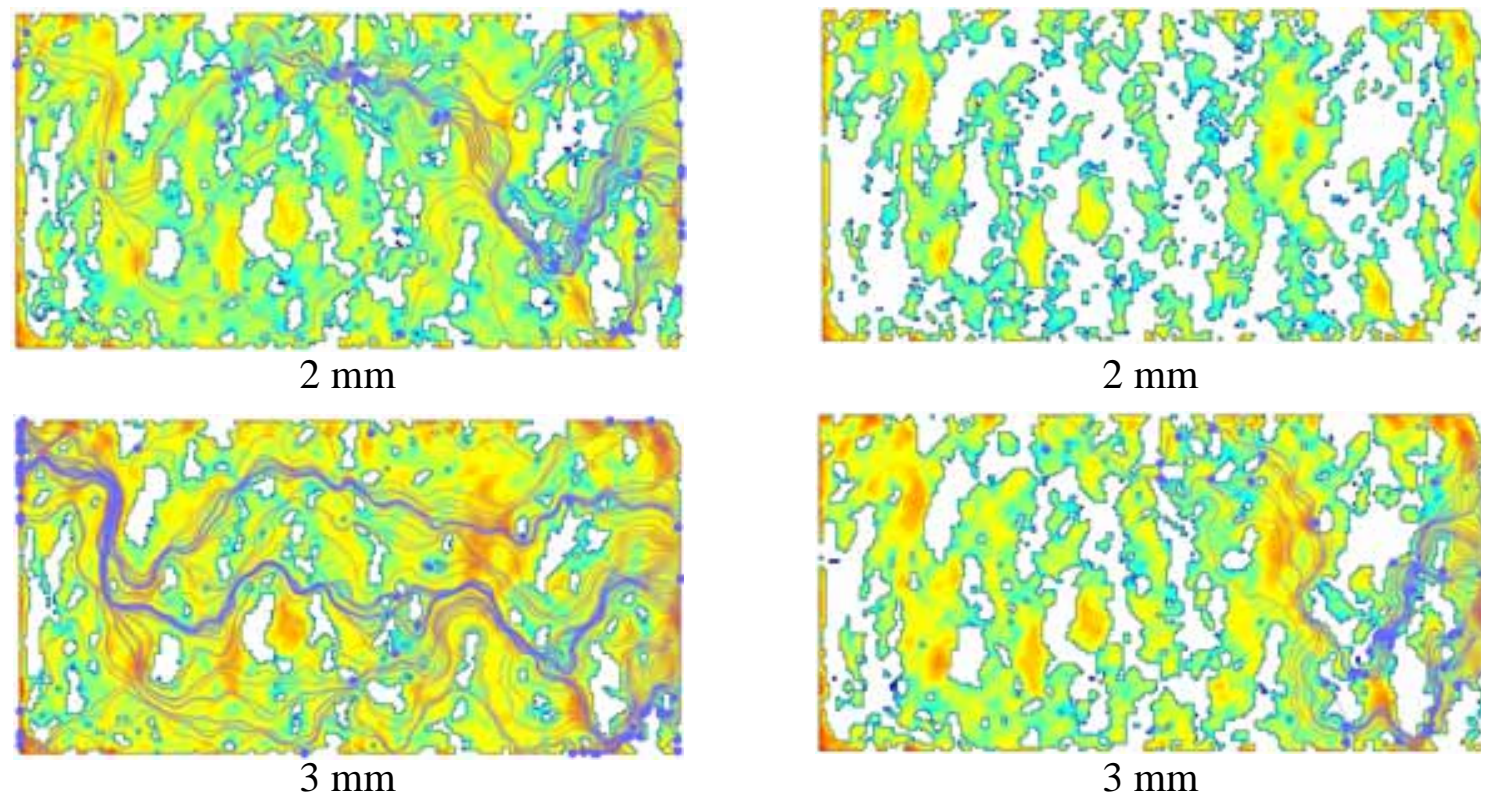

$3 \mathrm{~mm}$
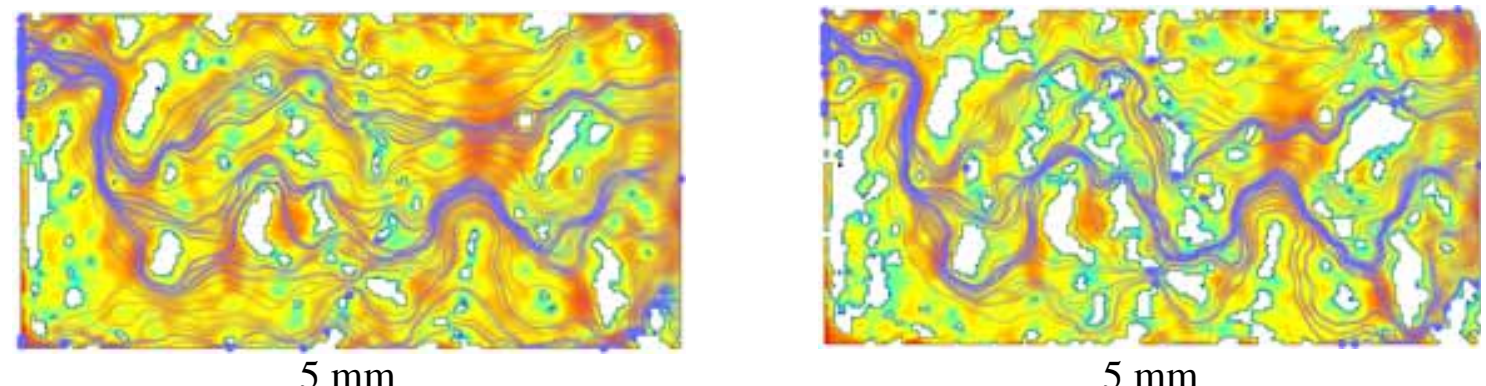

$5 \mathrm{~mm}$

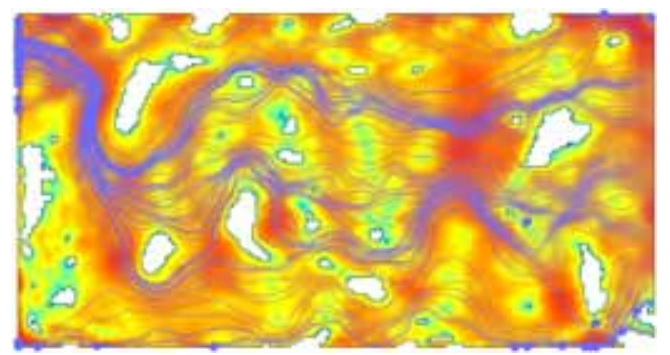

$10 \mathrm{~mm}$

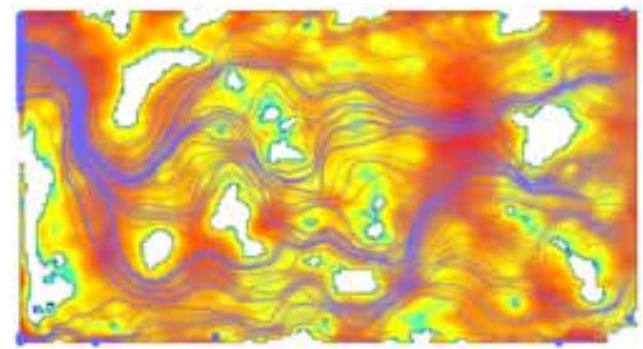

a)

$15 \mathrm{~mm}$

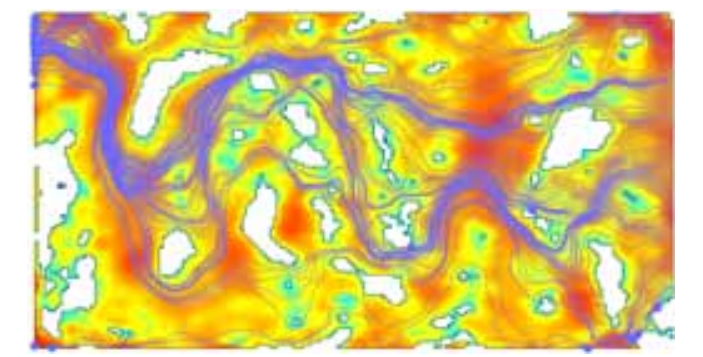

$10 \mathrm{~mm}$

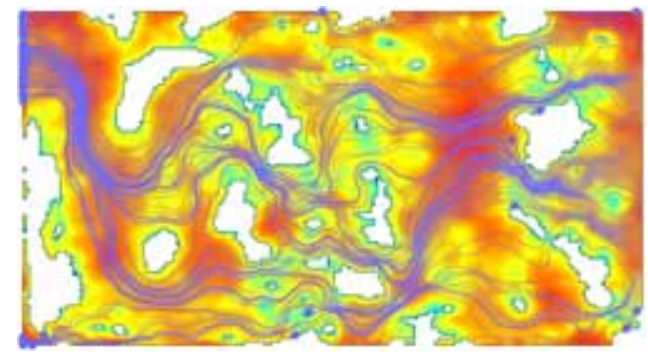

b)

$15 \mathrm{~mm}$

shear direction

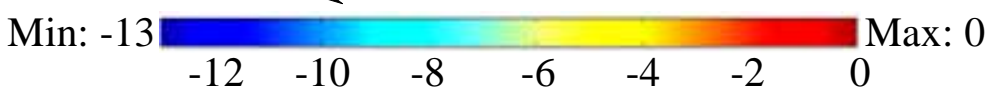

Figure 9. The change of particle travel paths with transmissivity evolutions for the particle movement parallel with the shear direction at different shear displacement of 2, 3, 5, 10 and $15 \mathrm{~mm}$ for fracture sample, J1 under two normal stress cases, a) J1-1 (CNL, 1.0 MPa) and b) J1-2 (CNL, 1.5MPa). The legend shows the order of magnitude of the fracture transmissivity $\left(\mathrm{m}^{2} / \mathrm{sec}\right)$. 

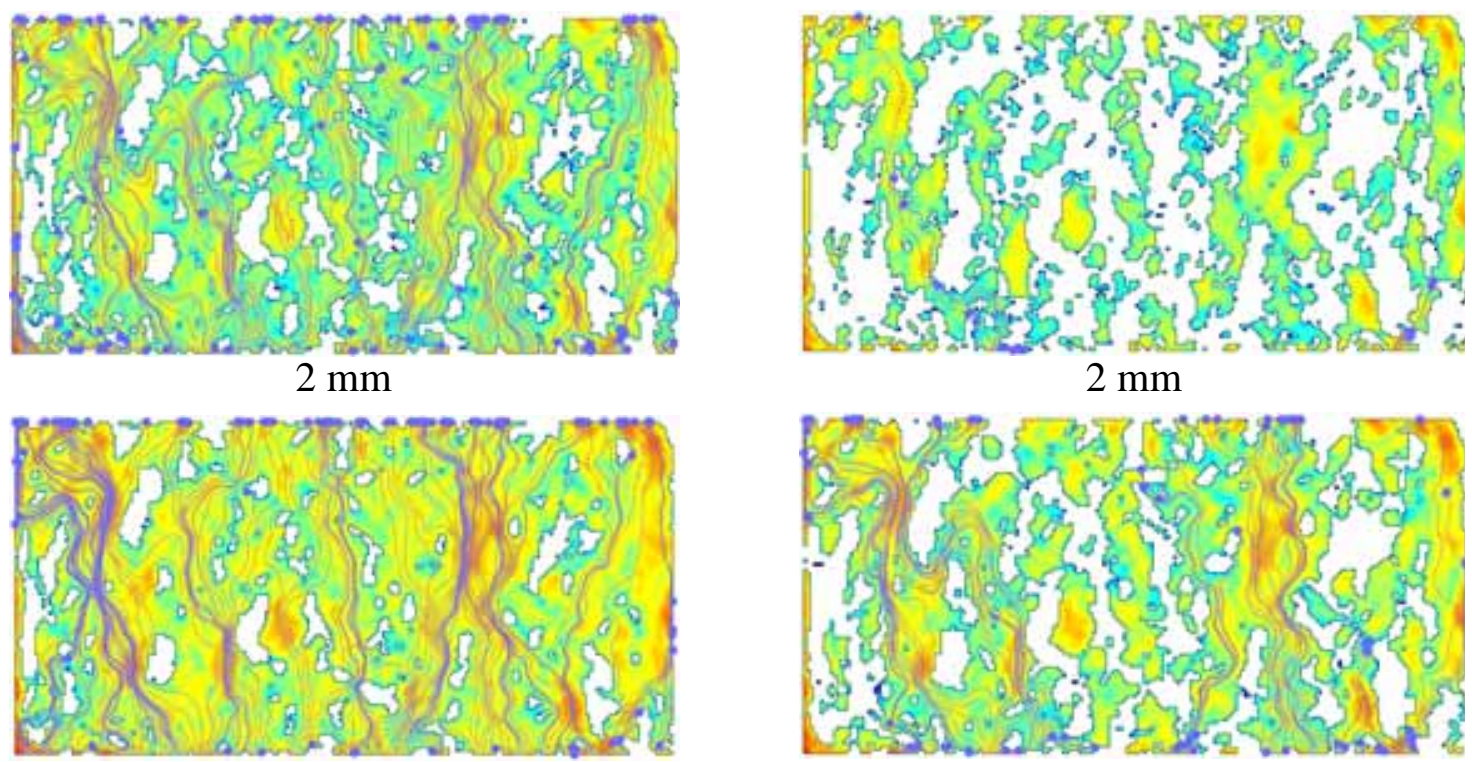

$3 \mathrm{~mm}$

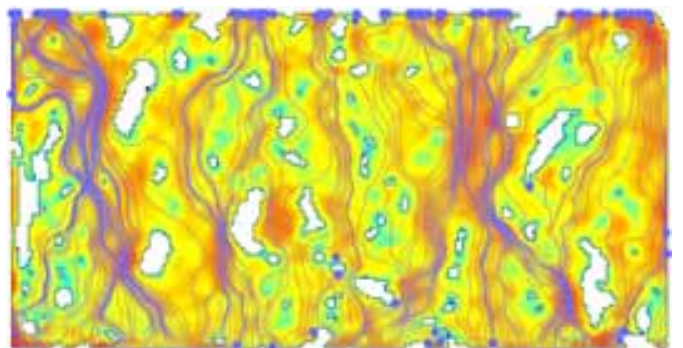

$5 \mathrm{~mm}$

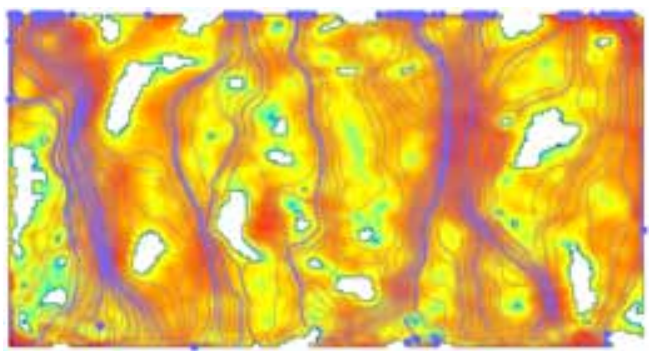

$10 \mathrm{~mm}$

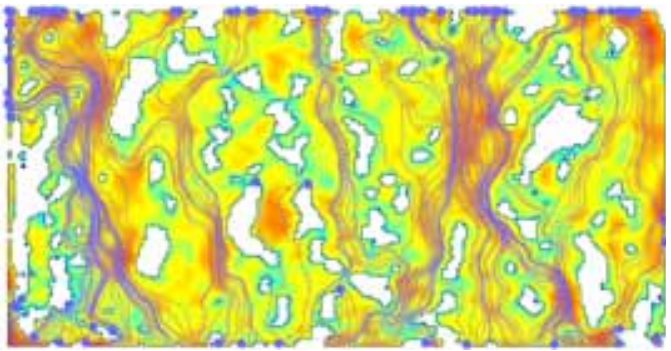

$5 \mathrm{~mm}$

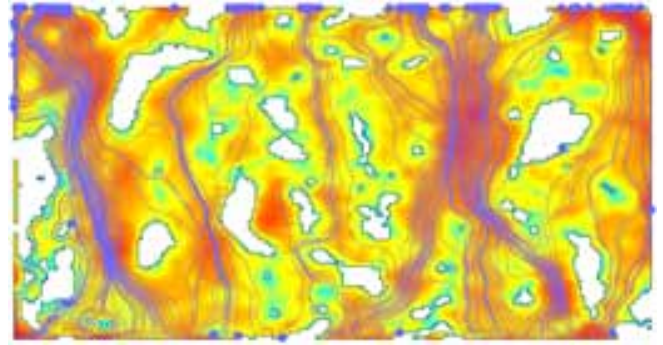

$10 \mathrm{~mm}$

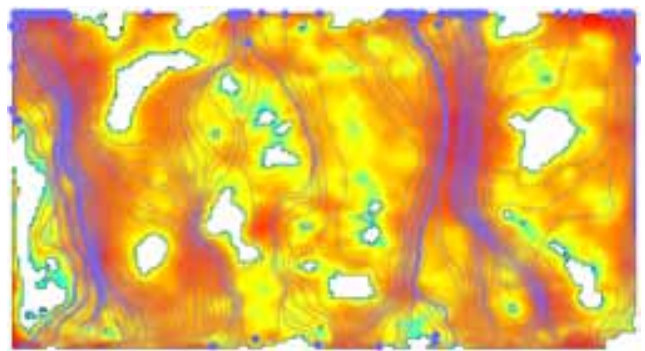

a)

$15 \mathrm{~mm}$

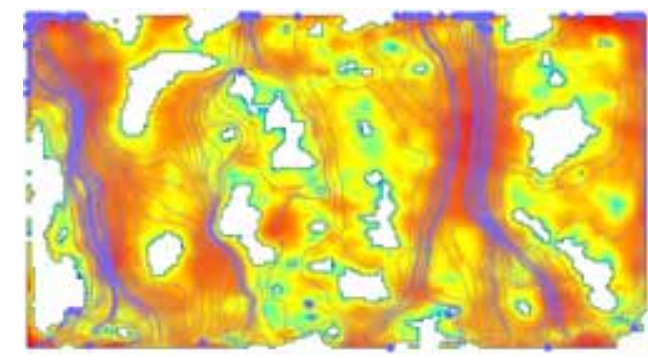

b)
$15 \mathrm{~mm}$

shear direction

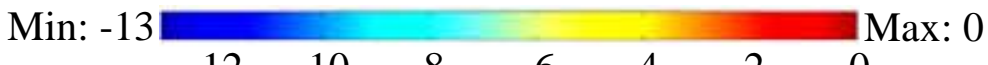

$\begin{array}{lllllll}-12 & -10 & -8 & -6 & -4 & -2 & 0\end{array}$

Figure 10. The change of particle paths with transmissivity evolutions for the particle movement perpendicular to the shear direction at different shear displacement of 2, 3, 5, 10 and $15 \mathrm{~mm}$ for fracture sample, J1 under two normal stress cases, a) J1-1 (CNL, 1.0 MPa) and b) J1-2 (CNL, 1.5MPa). The legend shows the order of magnitude of the fracture transmissivity $\left(\mathrm{m}^{2} / \mathrm{sec}\right)$. 


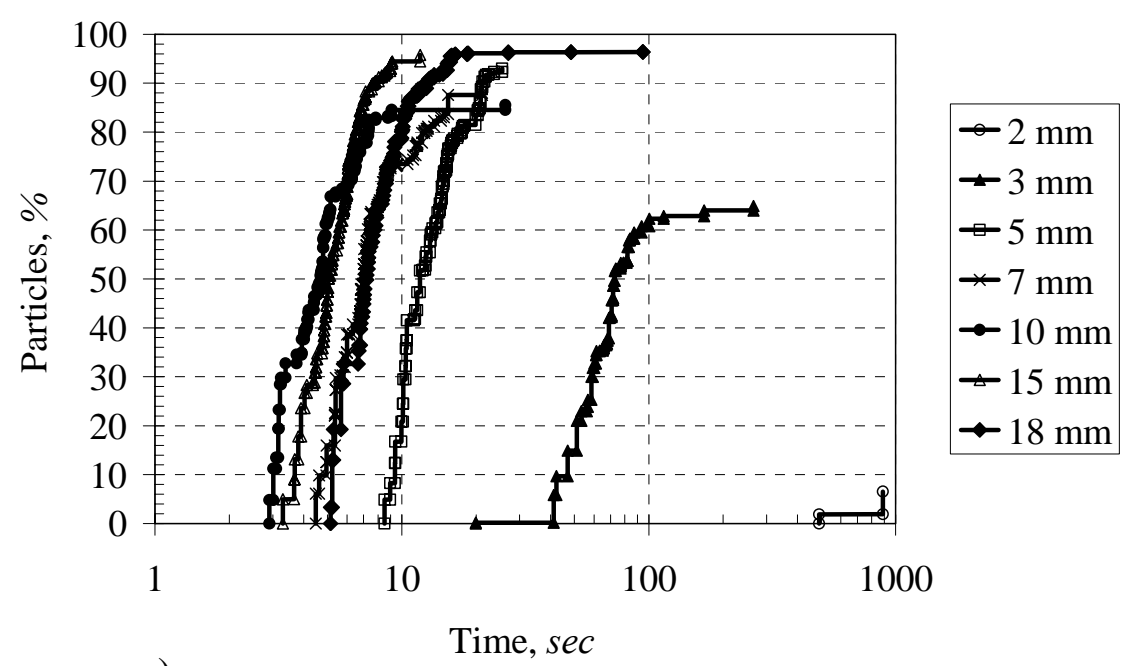

a)

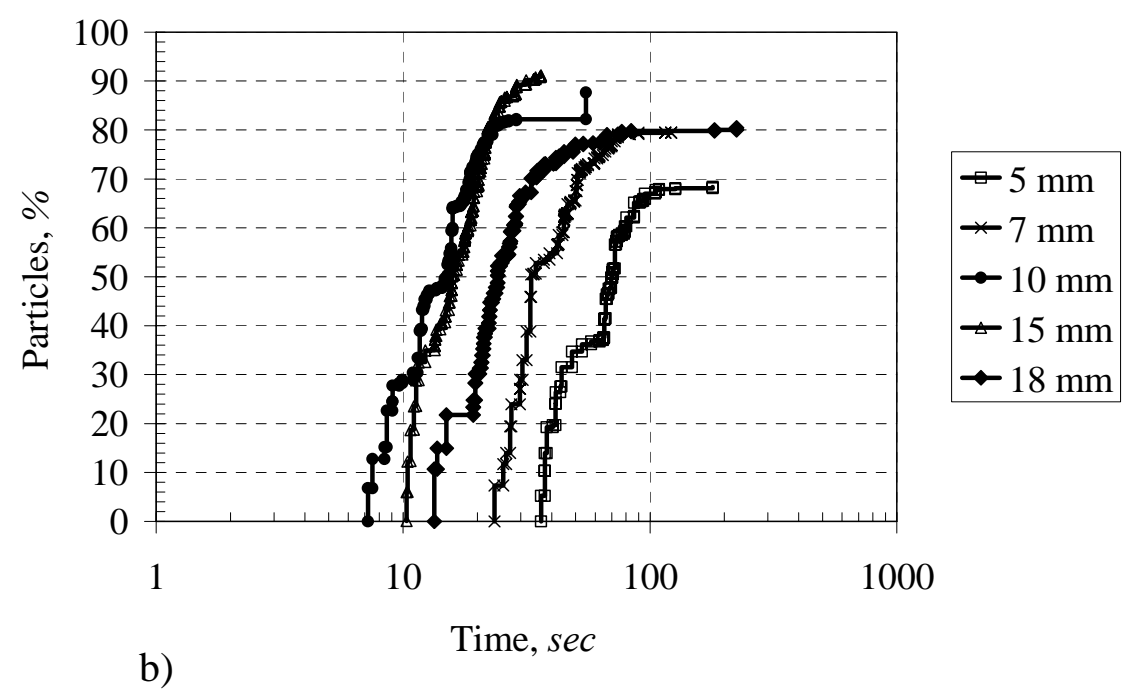

Figure 11. Breakthrough curves for particle transport with overall flow parallel with the shear direction at different shear displacement for fracture sample, J1 under two normal stress cases, a) J1-1 (CNL, 1.0 MPa) and b) J1-2 (CNL, 1.5MPa). 

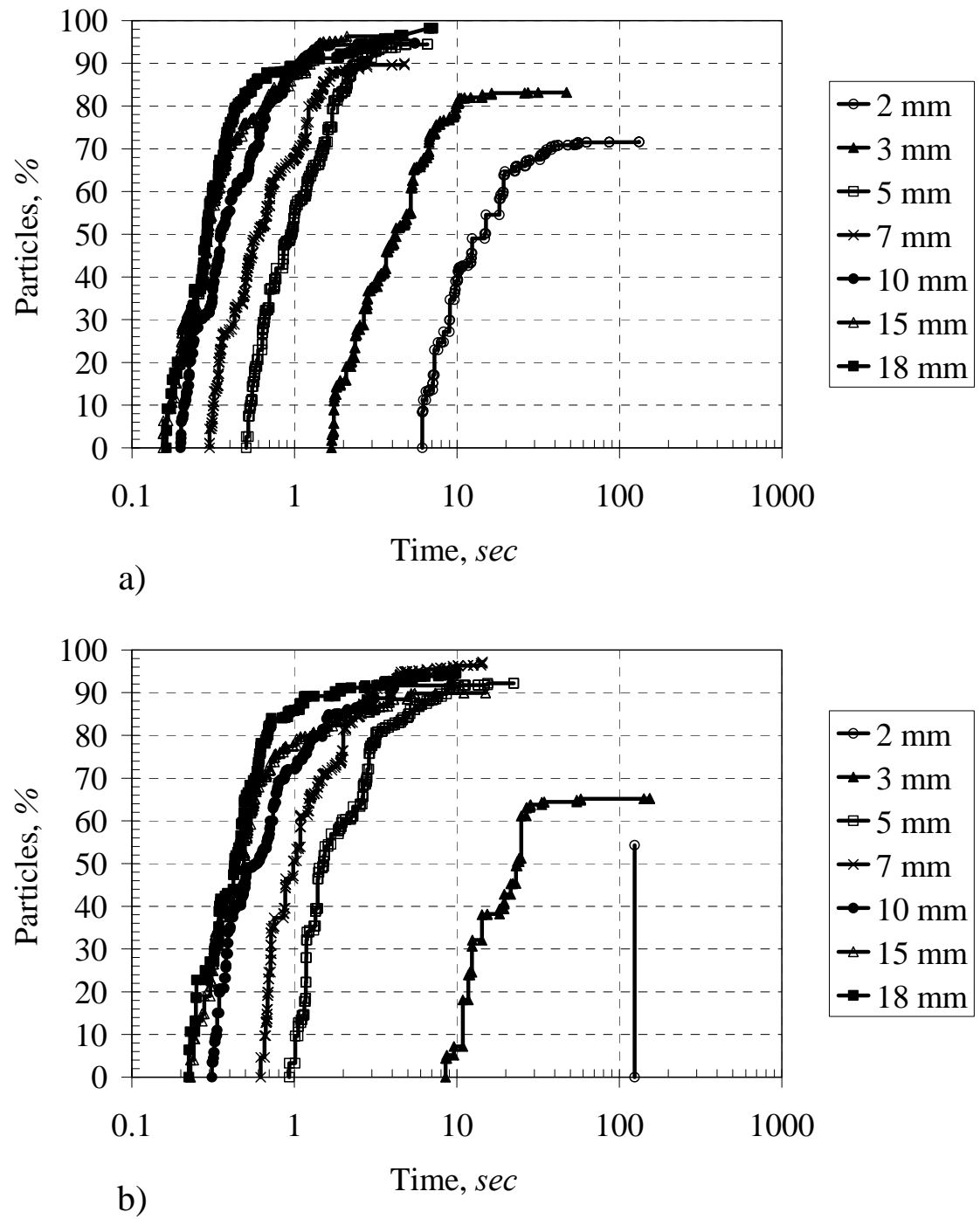

Figure 12. Breakthrough curves for particle transport with overall flow perpendicular to the shear direction at different shear displacement for fracture sample, J1 under two normal stress cases, a) J1-1 (CNL, 1.0 MPa) and b) J1-2 (CNL, 1.5MPa). 


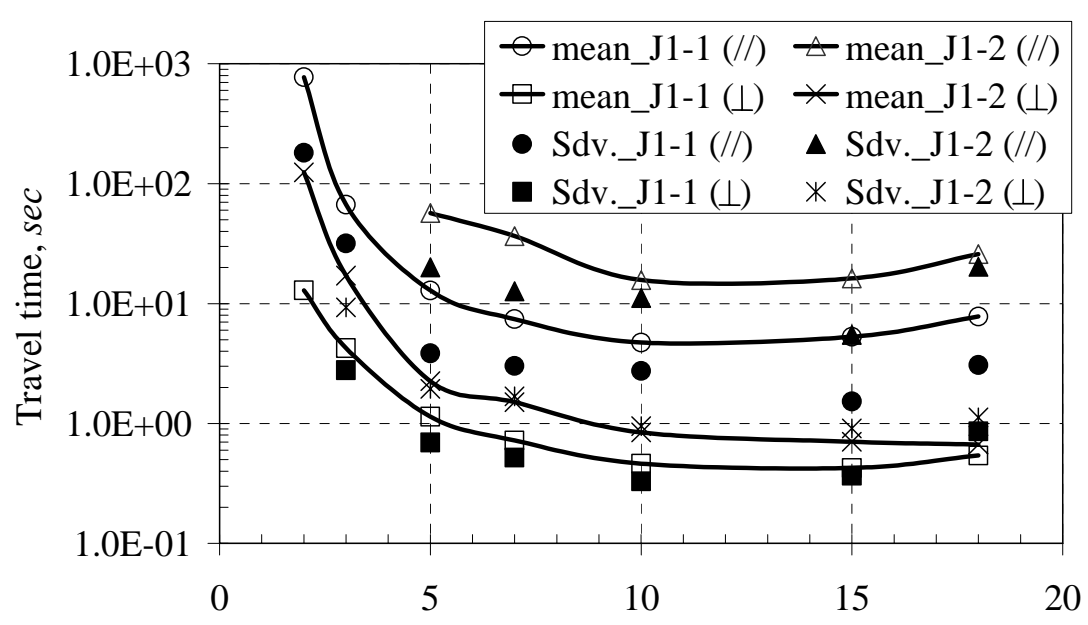

a)

Shear displacement, $\mathrm{mm}$

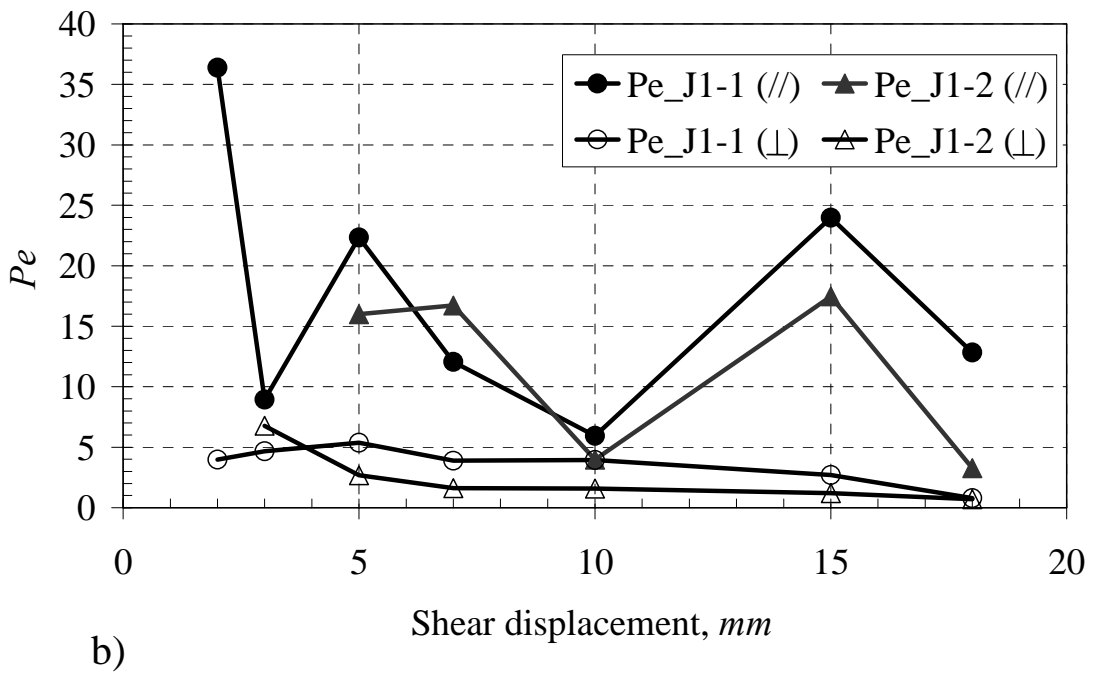

Figure 13. a) Mean and standard deviation of particle travel time and b) calculated Péclet numbers for particle transport with overall flow parallel with and perpendicular to the shear direction as a function of shear displacement for fracture sample, J1 under two normal stress cases, J1-1 (CNL, 1.0 MPa) and J1-2 (CNL, 1.5MPa). 